\title{
Metal Additive Manufacturing in the Commercial Aviation Industry: A Review
}

\author{
Annamaria Gisario ${ }^{a}$, Michele Kazarian ${ }^{b}$, Filomeno Martinac, Mehrshad Mehrpouya ${ }^{\mathrm{d}}{ }^{\mathrm{c}}$ \\ ${ }^{a}$ Dipartimento di Ingegneria Meccanica ed Aerospaziale, Sapienza Università degli Studi di Roma, Via Eudossiana \\ 18, 00184 Rome, Italy \\ ${ }^{\mathrm{b}}$ Airbus Group, 2rond-point Maurice Bellonte 31707 Blagnac Cedex, France \\ 'Welding Engineering and Laser Processing Centre, Cranfield University, Bedfordshire, MK43 OAL, UK \\ dDipartimento di Ingegneria, Università degli Studi Roma Tre, Via Vito Volterra 62, 00146 Rome, Italy \\ Corresponding e-mail: mehrshad.mehrpouya@uniroma3.it, (+39) 644585272 \\ ORICID: 0000-0001-8939-7937
}

\begin{abstract}
The applications of Additive Manufacturing (AM) have been grown up rapidly in various industries in the past few decades. Among them, aerospace has been attracted more attention due to heavy investment of the principal aviation companies for developing the AM industrial applications. However, many studies have been going on to make it more versatile and safer technology and require making development in novel materials, technologies, process design, and cost efficiency. As a matter of fact, AM has a great potential to make a revolution in the global parts manufacturing and distribution while offering less complexity, lower cost, and energy consumption, and very highly customization. The current paper aims to review the last updates on AM technologies, material issues, postprocesses, and design aspects, particularly in the aviation industry. Moreover, the AM process is investigated economically including various cost models, spare part digitalization and environmental consequences. This review would be helpfully applied in both academia and industry as well.
\end{abstract}

KEYWORDS: Additive manufacturing; 3D printing; Aerospace; Aviation industry; Power Bed Fusion, Direct Energy Deposition.

Table of Contents

Abstract.

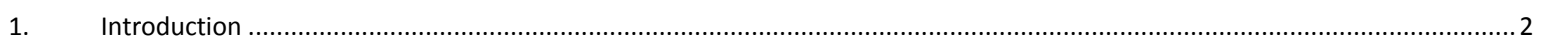

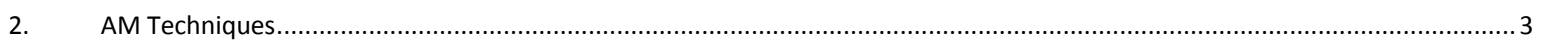

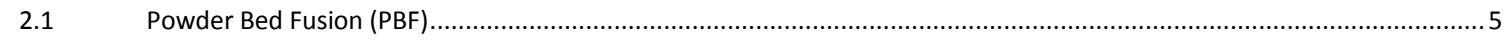

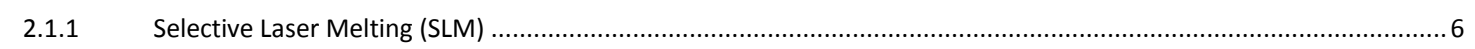

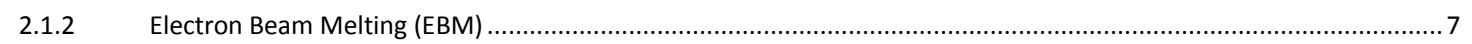

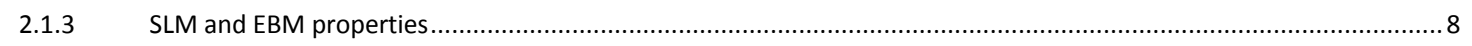

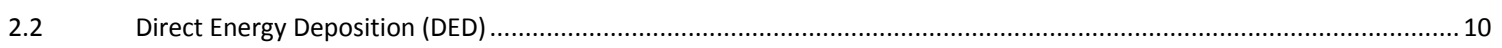

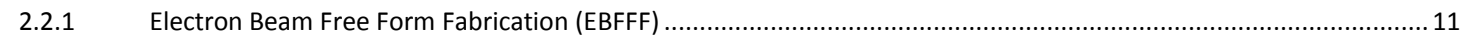

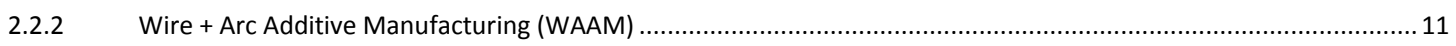

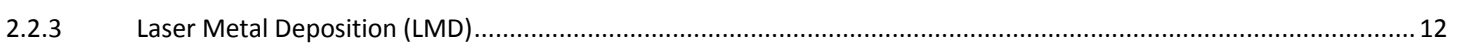

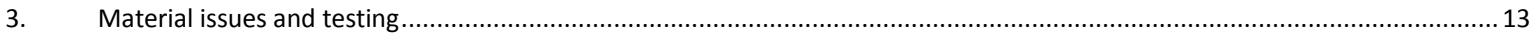

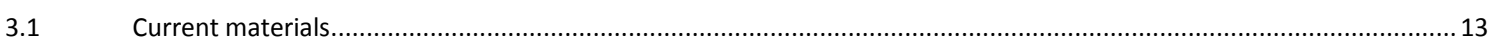




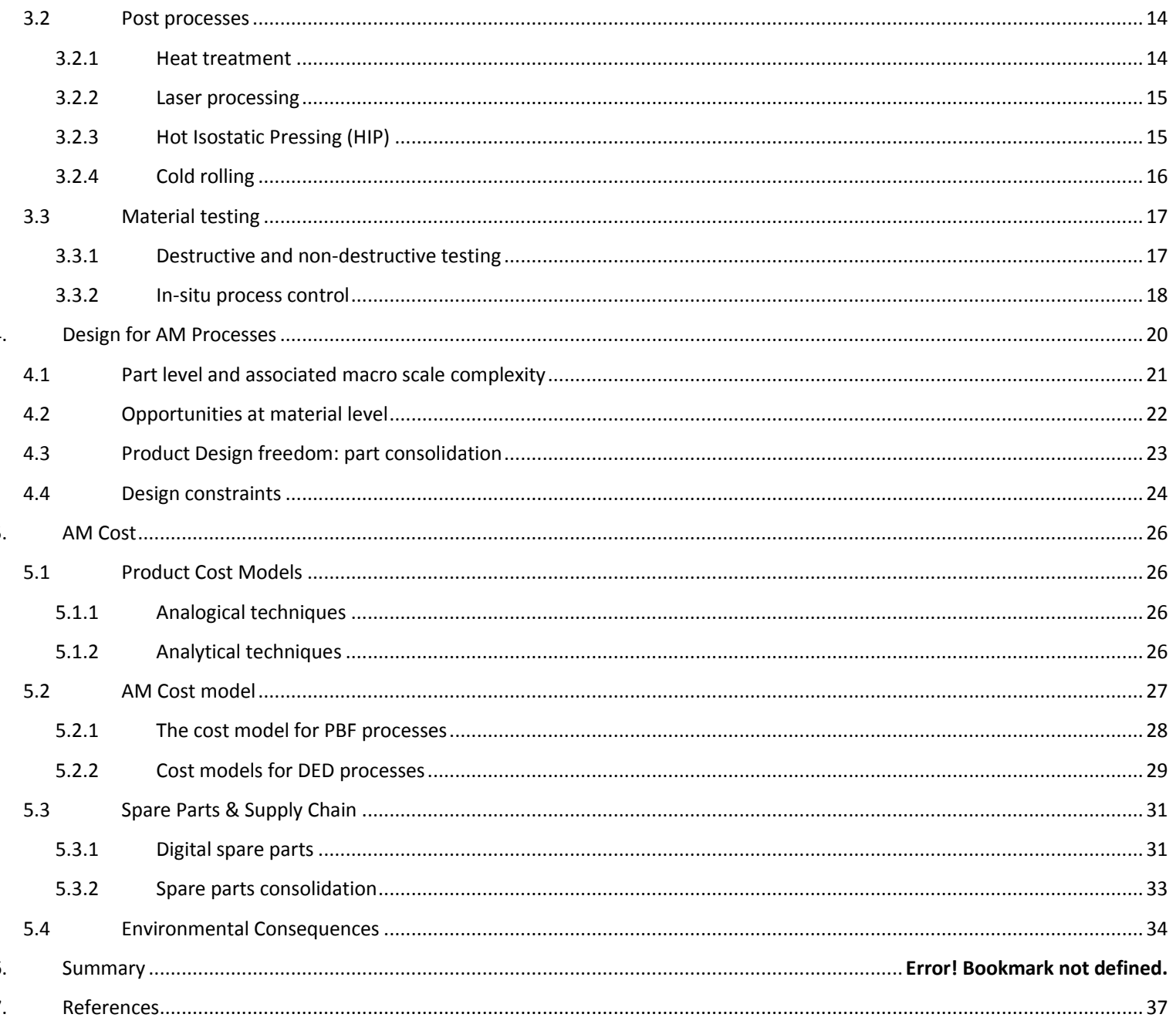

\section{INTRODUCTION}

Additive Manufacturing (AM) attracts many attentions among industrial and academic practitioners due to a number of possible improvements of production systems such as reducing waste materials, shorter manufacturing lead times, high flexibility, feasibility of complex geometry products, and shorter product development cycle [1-4]. The market demand for highly customized objects, together with the introduction of new business models and leaner supply chains, is driving the interest of AM technologies [5, 6].

According to the annual worldwide report on the progress of AM technologies, produced by Wohlers Associates, the global revenue from AM production and associated services grew from $\$ 2.25$ billion in 2012 to more than $\$ 6$ billion in 2016 and the forecast is to reach $\$ 21$ billion by 2020 [7]. This growth is also due to the advancement in technology and material development. In the early technology development stage of about 30 years ago, the AM processes were dedicated to the fabrication of models and prototypes in industrial and academic R\&D environments. Later, AM was also used to create tooling like silicone casting molds, and during the last 10 years [8]. AM has been introduced for metallic end-user products. In 2012, just $28 \%$ of AM components were functional while in 2016 this percentage went up to almost 34\% [7]. Today, AM is advancing towards becoming a "true manufacturing platform that can produce the form, fit, and function of a component" [9].

Aerospace is one of the industries where AM can find most likely applications, and the major players like Airbus, Boeing, NASA Lockheed Martin are heavily investing in the development of this technology [10-12]. Indeed, for the 
aircraft industry, one of the main drivers of improvement is the weight reduction of flying components. In the case of manufacturing cost reduction, it is worth noting that structural materials used in the aircraft industry must be highly performant - such as Titanium alloys or composite materials - and thus quite costly. An interesting opportunity is therefore to improve the Buy-to-fly (BTF) ratio, that is, the ratio between the mass of raw material needed for a given production and the final mass of the manufactured part [13-15]. Currently, by using the Conventional Manufacturing (CM) processes, the BTF ratio for aircraft components is in the range of 12:1 - 25:1 and results in very poor material efficiency [16].

Another important driver for lighter aircraft components is the operational and societal impact: fuel economies bring along better opportunities for airlines who can better develop their network and service offer, and for passengers who can fly further and cheaper. Also, as aviation generates about $9 \%$ of global greenhouse gas (GHG) emissions related to transport, and because the growth forecast implies tripled fuel consumptions by 2050, increasing fuel efficiency might help to reduce the environmental impact of aviation $[16,17]$.

The purpose of this study is to have a general picture of AM opportunities and costs in the commercial aviation industry, by evaluating the benefits of using such technologies in the supply chain and particularly for spare parts. The study tries to go beyond the technical and economical comparison with conventional manufacturing techniques and wants to widen the perspective on the multiple ways AM creates value in the global supply chain of commercial aviation, also evaluating the environmental impact that AM large-scale diffusion could have in the long term.

In the following, the main AM technologies and printing methods are described in section 2 . Then, section 3 briefly introduces the current materials which applied in the aviation industry, methods for improving and controlling the process and parts quality are detailed such as post-processing techniques and in-line process monitoring systems. After that, some advantages that could derive from the application of AM technologies in the manufacturing systems of aircraft components are discussed in section 4. In this section, the possible benefits in terms of design complexity and flexibility are shown. These are discussed in terms of performance enhancements due to design optimization or in terms of weight reduction. The last section, section 5 , is dedicated to cost models for evaluation of AM technologies feasibility, either compared to conventional manufacturing techniques or among different AM processes. Also, the effects of AM in the supply chain and the entire product life cycle is evaluated, as well as the effect of design consolidation through AM on the spare parts market.

\section{AM TECHNIQUES}

AM process is able to create physical parts starting from digital input. In order to achieve the desired geometry, various operational parameters should be defined in the software, such as the tool paths and projection patterns, and they depend on the material used and equipment. This is one of the biggest advantages of AM: manufacturing parts with little need for specific tooling for shape definition. The first patent related to AM goes back to 1920 when Ralph Baker filed the US Grant US1533300A with the title "Method of making decorative articles" [18]. Since the late 1960s and early 70s, researchers made the first patents of modern AM processes, enabled by the invention of computers, of resin polymers, and CNC machines, together with advancement in CAD/CAM development [19]. In 1989, MIT developed the groundbreaking 3D printing process. Thanks to increasing dedicated research studies and the industry interest for this promising technology, other AM processes were developed too. A new generation of cheap and powerful computers allowed the introduction of AM technologies for production environments just between 1980 and 2000s, as better quality 3D designing and modeling became more widespread.

Nowadays, various AM technologies are available in the market and industry. Some of them are already used for production and some others are still in the development phase. Figure 1 shows AM processes based on the heat source utilization which categorized in three different groups including a laser beam, electron beam, and arc plasma. As visible in this category, there are various capabilities of the AM process which can be applied for various 
materials and applications. Accordingly, each process should be investigated separately to discover the materials and mechanical properties of the final products.

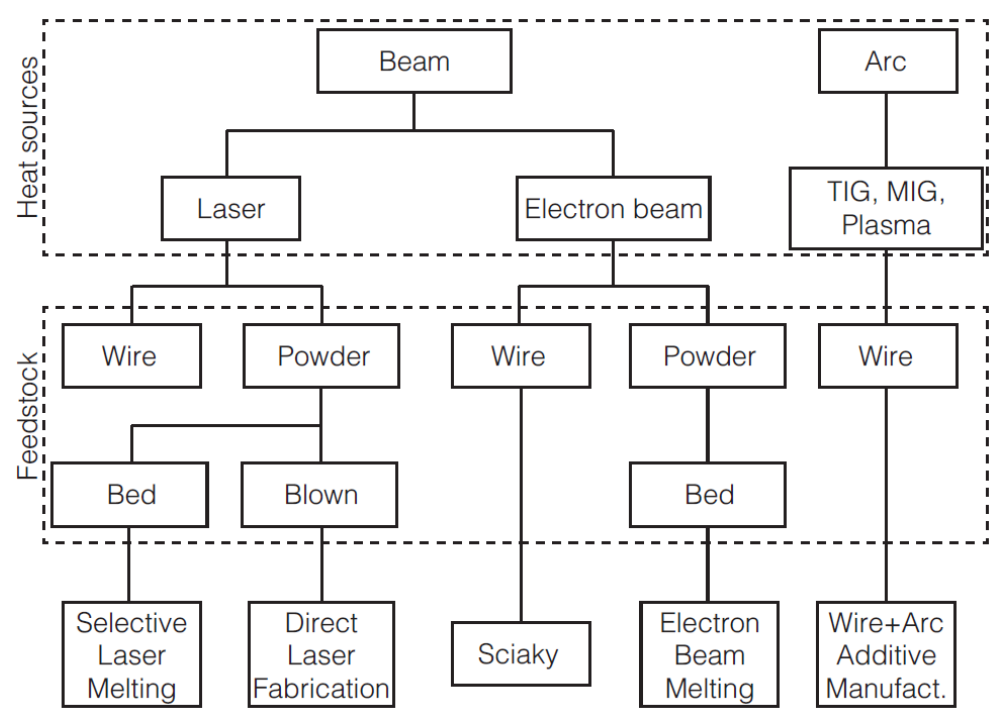

Figure 1. The principal metal AM processes based on heat sources utilization [20]

Also, ASTM standard [21], with its sub-committee F42 that is responsible for AM technologies, defined different types of AM technologies, including sheet lamination, binder jetting, material jetting, vat photopolymerization, material extrusion, powder bed fusion, and direct laser deposition. Figure 2 shows a schematic of all AM technologies and the application in various industries based on the ASTM category.

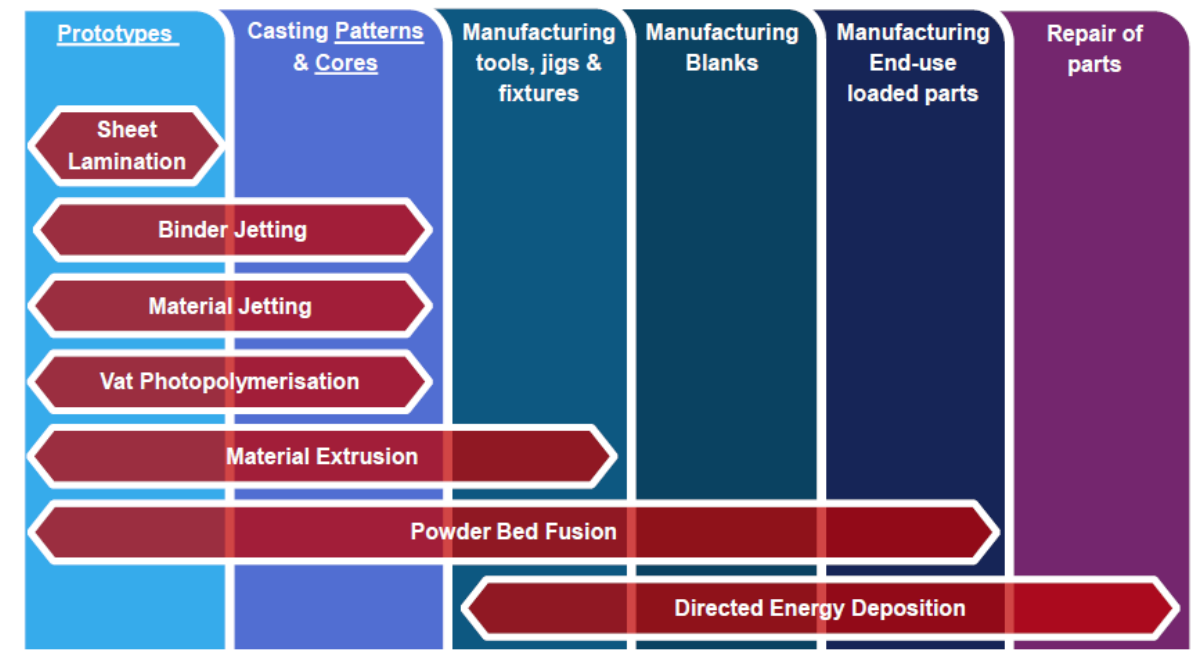

Figure 2. Additive Manufacturing process types and applications [21]

Below, a generic description of some possible AM applications are listed and briefly explained, afterward more detail including specificities of the processes and case studies are discussed in the literature.

\section{- Prototypes}


The use of AM allows performing rapid design iterations thanks to physical tests as opposed to the common "virtual" simulation used to optimize designs, thus enabling agility in new product developments [22]. Most of AM processes are suitable for making prototypes [23], but not all of them can create functional ones: for example, prototypes built by Material Jetting only have aesthetic properties and are therefore used for marketing purposes. On the other hand, Powder Bed Fusion can create fully functional prototypes for product testing.

\section{- $\quad$ Casting patterns and cores}

For a low number of cast parts with high complexity, Binder Jetting can be used to create casting cores made of sand. Alternatively, a wax or polystyrene casting pattern can be directly produced by AM without making a tool for the purpose [24].

\section{- Manufacturing tools, jigs, and fixtures}

From an economic and cost perspective, these applications are good candidates for AM technologies as they are typically low volume productions or even one-off, and they can be very complex geometries [25]. Mostly done by Powder Bed Fusion processes in polymers or metals, reaching maturity for this application would allow significant savings in terms of production lead time and non-recurring-cost (NRC) reduction.

\section{- Manufacturing blanks}

In this work, blanks will be referred to like parts with a shape that is very close to the final component's one, and where the latter can be achieved with some additional machining. The suitable technologies for this application are Powder Bed Fusion (PBF) and Direct Energy Deposition (DED).

\section{- Manufacturing end-user parts}

Some AM processes are capable to produce parts with the same properties of those produced with conventional technologies, or even higher sometimes. The geometric flexibility of processes such as PBF could allow the topological optimization of parts [26]. Moreover, it is possible to produce a whole assembly through the integration of its constituent components into a single and more complex one. In aviation, where each component needs to be qualified as airworthy, the integration could save huge qualifying efforts. On the other hand, the limited number of standards and case studies available could make it difficult to convince authorities regarding the reliability of the parts.

\section{- $\quad$ Repair of parts}

Lastly, and only by DED, it is possible to add material to repair damaged or worn metal components. Effectively, this could be compared to CNC welding or cladding processes but would have to be complemented by sophisticated metrology and design tools in order to be effective. Therefore, repair of parts using AM would only be feasible in planned and repeatable scenarios, and where scrapping the part would have a bigger impact in terms of value or spare part availability $[27,28]$.

\subsection{POWDER BED FUSION (PBF)}

PBF process can be used either with metals or with polymers [26, 29]. Quite simplistically, and as the name summarizes, the process consists of raw material in the form of powder being molten onto a "bed", which is a substrate plate, to create the final part [30]. One advantage of PBF processes is that fabrication time does not depend on parts complexity, and it is controlled by the melted material volume instead. The principal elements that are common in all PBF processes are [31];

- Energy source: This can be a laser heat source or an electron beam and has the critical function of fusing powder particles together.

- Scanning motion device: This system allows to precisely induce fusion only in determined areas according to the design, by controlling the movement of the heat source over the powder bed.

- Powder feeder and roller: This is a mechanism for adding, smoothing and compressing the powder on the upper layer. 
- Elevator: This mechanism is necessary to lower the bed after each layer has been scanned by the heat source in order to allow the feeder to add another layer.

- Enclosed chamber: The ambient properties need to be controlled, as it is fundamental for achieving optimal mechanical properties of the part.

There are three main types of PBF processes: Selective Laser Sintering (SLS); Selective Laser Melting (SLM); and Electron Beam Melting (EBM). SLS process is almost identical to SLM, however, the main difference is the application of high-power laser in the SLM process which melts the metal powder into the solid 3D fabricated part. According, this review focuses only on SLM and EBM processes, which are quite commonly applied in the research for aerospace parts production. These two technologies will be reviewed in detail in the following paragraphs.

\subsubsection{Selective Laser Melting (SLM)}

Various metallic materials can be used in the SLM process and they need to be certified in their chemical compositions and in the grain size before the process $[32,33]$. In order to achieve the satisfactory surface quality of the part, the grain size does not have to exceed $100 \mu \mathrm{m}$, and the median grain size should be preferably in the range of 45-63 $\mu \mathrm{m}$ [34]. The SLM machine has a closed chamber, which is flooded with an inert gas such as Argon in order to avoid oxidation of the particles [35]. Inside, a fabrication piston lowers the construction plate on which the object is being fabricated. At the same time, another piston next to the first one pushes up the powder so that a roller can distribute a layer evenly on top of the object. After that each layer of powder is positioned, a laser is generated and directed through a scanner into the chamber, and it shapes the fused layer according to the CAD design. The process is repeated layer after layer. Figure 3 illustrates a schematic of all steps in the printing process of powder bed machines.

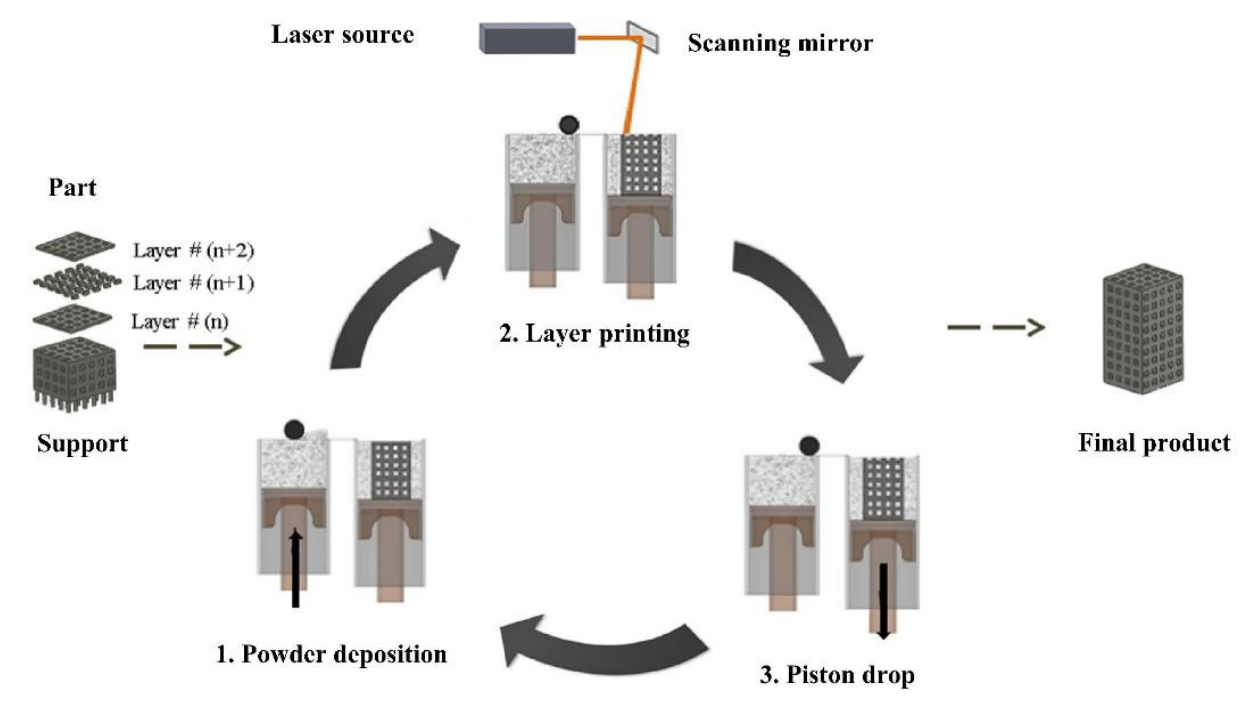

Figure 3. A schematic of the operation of powder bed machines including three repeatable steps; power deposition, layer printing, and piston drop [36]

The SLM machines allow layer thickness ranging between 10-100 $\mu \mathrm{m}$ but, in order to achieve higher part resolution and surface quality, it is preferable to use a layer thickness of averagely $30 \mu \mathrm{m}$. On the other hand, going for a larger thickness allows increasing the overall production speed, improving the process stability, and reducing costs $[37,38]$. Once the object is complete, the excess powder that has not been molten can be sieved for reuse. Since the chamber is filled with powder, the geometry of the part and its orientation in the chamber needs to be studied and specified in order to avoid powder being trapped into cavities or in places difficult to access. Moreover, 
support structures might be required depending on the geometry and its position into the chamber. these structures must be used for anchoring the part to the substrate plate and minimize distortions due to the powder spreading $[39,40]$.

Some examples are shown in Fig. 4 regarding the effect of part orientation in the chamber. Support structures also influence the final quality of the part and the amount of post-processing required, so they need to be carefully taken into account too $[41,42]$. A great advantage of SLM is that a batch of the same parts can be produced at the same time, but different parts can also be put together (if made of the same material) the limit being the volume size of the chamber.

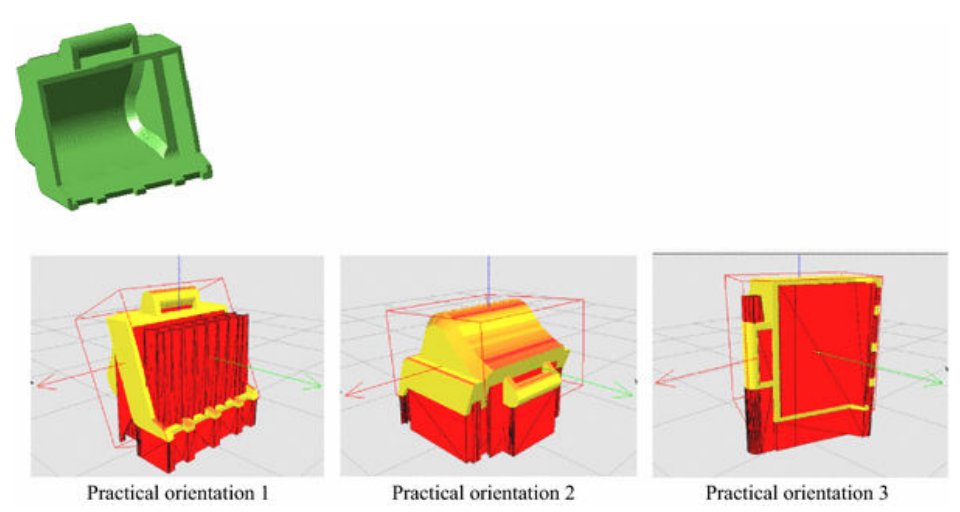

Figure 4. Practical alternative orientation set for AM of a part [43]

Residual stresses are quite important in the SLM process [44, 45]. They create during the SLM process when the laser expands the material and then it shrinks after the laser has moved. The part is therefore subject to large internal stresses during deposition due to material's shrinkage during solidification. Stresses could cause the support structures to fail or even the part itself in extreme cases [46]. In order to avoid this, stress relief heat treatment needs to be done before separating the part from the substrate $[47,48]$. In addition, to mitigate the effect of residual stresses, the chamber could be heated above the stress relieving temperature. After cleaning the excess powder and making the stress relief heat treatment, the support structures have to be taken apart. Firstly, the parts are cut from the substrate plate. Secondly, the supports are manually removed from the parts. In order to avoid having support structures in areas with poor access, the orientation of the parts in the chamber needs to be evaluated. Finally, the printed parts, if required, need to employed post processing or treatments in order to improve porosity, surface roughness, and generally mechanical properties of the parts.

\subsubsection{Electron Beam Melting (EBM)}

The EBM process is very similar to SLM, the main difference being the heat source: an electron beam is used instead of the laser beam $[49,50]$. Rafi et al. argue that the electron beam's capability of penetrating the powder is higher than that of the laser beam, allowing faster scanning compared to SLM [51]. Figure 5 schematically represents the EBM process in various steps. The first layer creates from the melted powders from the base of the product in the vacuum. All layers together can make a solid form or the support structure with a thin layer [52]. Also, the preheating process can take place with a set of defocused beam passes including high power and speed. The build table moved lower after one making one layer and the rest of powders are delivered to hoppers. After that, this process repeats again and again until the final object is completed [53, 54]. In order to avoid residual stresses in the final object, which could negatively affect the mechanical properties as already seen for SLM, the EBM machines optimize the process temperature so that it remains constantly high in the chamber throughout the entire process [55]. After the build, the parts need to undergo the same processes of SLM, that is, support structures removal and post-processing for improved properties. 


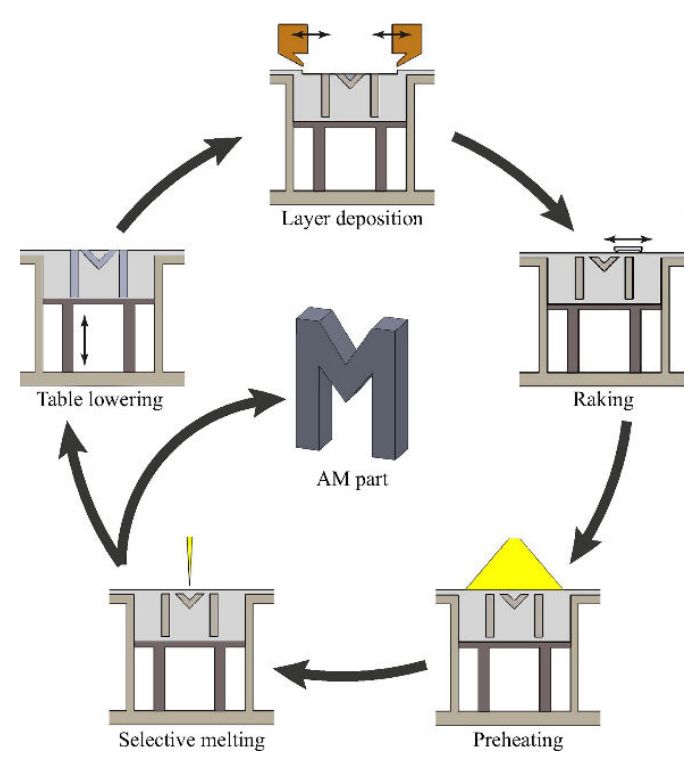

Figure 5. A schematic of the EBM process [53]

\subsubsection{SLM and EBM properties}

The two processes work in a very similar way and as explained the main operational differences are the heat source and the chamber temperature $[56,57]$. The laser beam of SLM allows having a weld pool as narrow as $0.3 \mathrm{~mm}$ compared to the $1 \mathrm{~mm}$ minimum feature size achievable with the electron beam source. This also implies a different surface quality.

\section{- Surface Quality}

The surface of the fabricated samples has a great influence on the mechanical properties and consequently on the fatigue behavior of the sample. For this reason, the additive manufactured parts must be machined for having a good surface quality for many applications. The parts fabricated by the SLM process have a smoother surface than EBM manufactured parts. It is due to higher scan speed in the EBM process compared to the SLM. This makes the EBM faster, then it results in a poor surface finish $[34,51,58]$. Also, the higher deposition precision of SLM comes at the cost of process velocity. Indeed, the deposition rate of SLM is typically $0.1 \mathrm{Kg} / \mathrm{hr}$, whereas an EBM machine can double that performance [59]. According to Busachi et al., the facts that the EBM process is done in a vacuum atmosphere and the powder is heated help to achieve $98 \%$ density and mechanical properties comparable to those achieved by conventional manufacturing techniques. On the other hand, SLM shows more defects related to higher thermal stress [60].

\section{- Residual stress}

Both SLM and EBM processes can typically deposit layers thicknesses ranging from 20-100 $\mu \mathrm{m}$ [61]. Nevertheless, differences in the microstructure may arise [62]. Comparing samples produced with the two processes it was found that in both cases the primary solidification structure is $\beta$, but because of the different cooling rates, differences would arise in the transformation from $\beta$ to $\alpha$ phase. In the SLM-made samples the final microstructure is complete $\alpha^{\prime}$ martensitic due to the high cooling rates (in the orders of $10^{6} \mathrm{~K} / \mathrm{s}$ ), which creates important residual stresses in the material. On the other hand, the EBM-made sample had an alpha lamellar morphology thanks to the chambers controlled the temperature at about $700^{\circ} \mathrm{C}$, which is well above the martensitic formation temperature and therefore does not need post-processing for reducing residual stresses [51].

\section{- Tensile Properties}

Tensile strengths of samples produced with EBM and SLM processes both results acceptable for Ti64 samples as shown in Fig. 6 [51]. As can be seen, the Yield Stress (YS) is quite inhomogeneous and range around YS=1100- 
1200MPa for SLM-fabricated Ti64 samples. Instead, EBM-fabricated samples show more stable values at around 850-900 MPa. This difference can be explained by the strong presence of martensitic microstructures due to the rapid cooling in the SLM process, as opposed to the alpha lamellar microstructure derived from the EBM heated chamber [38].
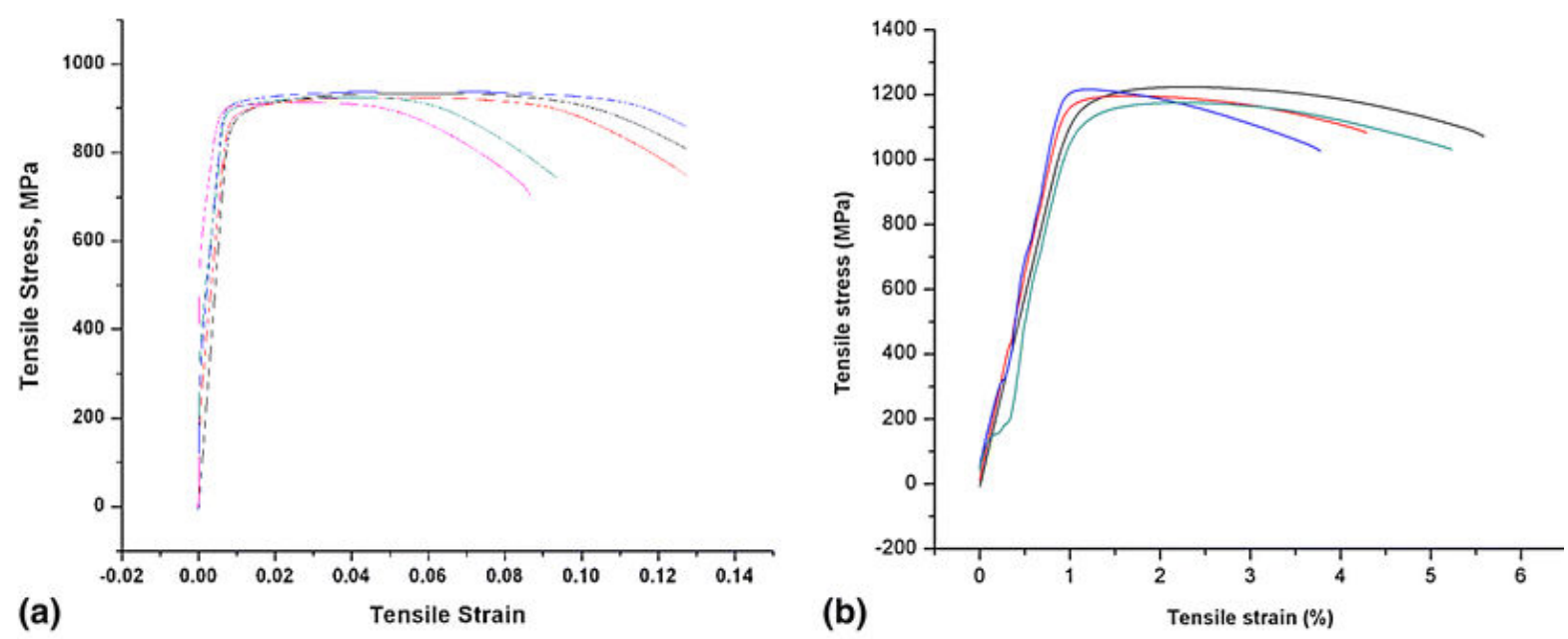

Figure 6. Tensile stress-strain plot for a) EBM specimen and b) SLM specimen [51]

Due to the martensitic microstructure, the Rockwell hardness test results higher for SLM-produced samples too (SLM-HRC: 41, EBM-HRC: 33). Lastly, the strain at break results much higher for EBM-produced parts (>8\% and up to $20 \%$ ) compared to the SLM ones (>4.5\%), meaning that SLM is capable of producing harder components but more fragile compared to EBM process [9]. It is worth noting that with both processes, YS and UTS tend to be about $5 \%$ higher when layers are deposited parallel to the stress direction. Therefore, particular attention needs to be done when orientating the parts in the chamber, according to their service design scope.

\section{- Fatigue properties}

Figure 7 shows another example for the fatigue behavior after 10 million cycles of the as-built samples of Ti64 show a limit of $550 \mathrm{MPa}$ for the SLM sample and $340 \mathrm{MPa}$ for the EBM one [51]. Again, the better fatigue resistance of SLM-built specimen is attributable to the martensitic microstructure that reduces dislocation movements. Fatigue cracks can reportedly initiate from large pores, but these would not have an effect on crack propagation instead. Crack nucleation seems to be more frequent with lamellar microstructures, as alpha lamellae pose less resistance to slipping one on the other than the acicular martensitic grains do [51,63,64].
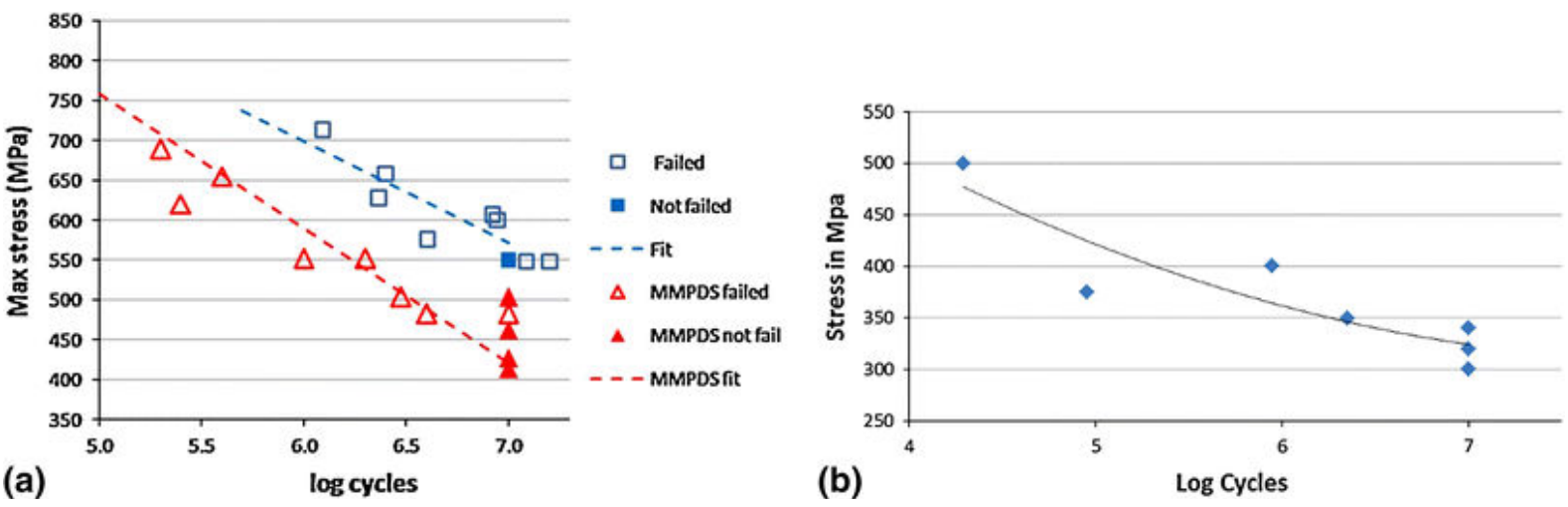

Figure 7. S-N curve for a) SLM and b) EBM specimens [51] 
Nevertheless, surface quality seems to be the main cause of fatigue crack initiation rather than internal defects [43]. Since Rz measures the distance between "peaks" and "valleys" of the surface, it is a good indicator of the impact on fatigue cracks. Indeed, cracks would likely nucleate from the "valleys" and having a large $R_{z}$ value increases this risk. Because the surface condition is so critical to the fatigue behavior of the part, a solution would be to machine out the surface of the part and eliminate the rough zone prone to crack nucleation. This could then expose internal pores on the surface, which would be less deep of $R_{z}$ so reducing the risk of crack.

\subsection{DIRECT ENERGY DEPOSITION (DED)}

Direct Energy Deposition processes have a strong advantage of high deposition rates compared to the PBF processes, thus they are more suitable for large components with high BTF ratios for aerospace applications: as a rough order of magnitude, PBF processes can achieve rates of about $0,1 \mathrm{Kg} / \mathrm{h}$, whereas DED processes reach average rates of $1 \mathrm{Kg} / \mathrm{h}$ and are capable of going up to $4 \mathrm{Kg} / \mathrm{h} \mathrm{[20].} \mathrm{Historically,} \mathrm{wire-fed} \mathrm{processes} \mathrm{have} \mathrm{received}$ less attention than powder-fed ones because of the complex geometries achievable with the latter and the consequent interest of the industry for this capability [65]. Nonetheless, demand for serial production parts is now showing that wire-fed DED processes can be good candidates for aerospace components. Overall, the main difference of DED processes compared to PBF is that DED generates the component by melting the powder at the same time it is being deposited on the substrate plate or on the previous layer [66-68]. The processes need to be either in a vacuum atmosphere or assisted by a shielding gas like argon [69]. Figure 8 shows a schematic of the DED process during the deposition of a pass with the aforementioned components.

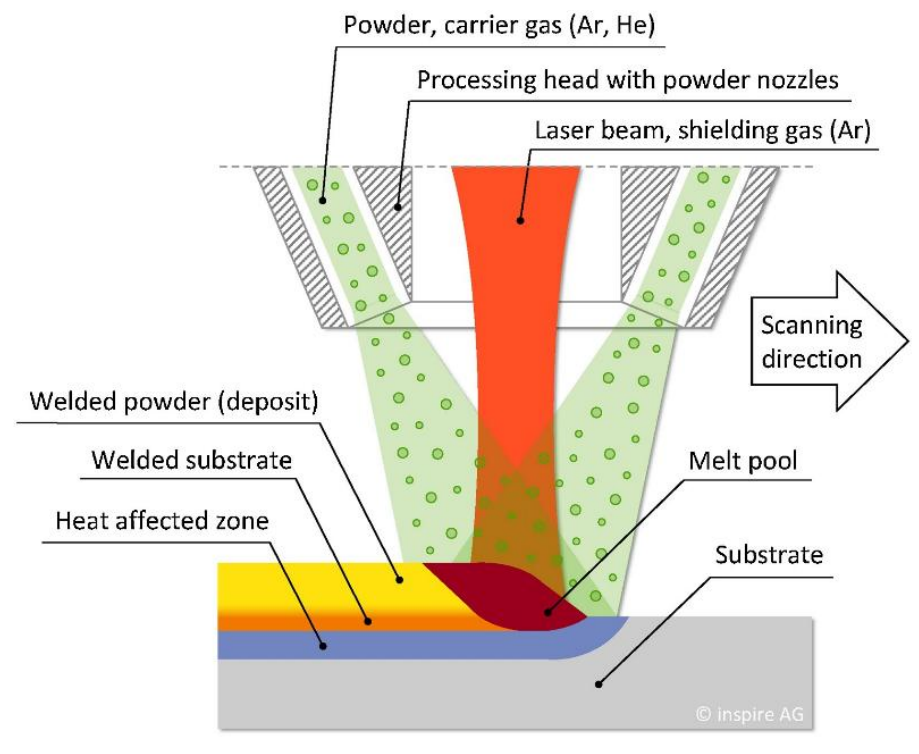

Figure 8. A schematic of the DED method [70]

Brandl et al. reported DED process on Ti-6AI-4V alloy and found that hardness decreases with distance from the top of the part, and that annealing the material does not affect this property. Regarding the static tensile properties, the average yield strength is in the range of 791-874 MPa, and the ultimate tensile strength at 872-940 MPa. The elongation varies greatly between $4.1 \%$ and $12.5 \%$. These results are comparable to the standard of Ti64 wrought or cast material. In addition, the fatigue properties are fully acceptable with around $800 \mathrm{MPa}$ at one million cycles [71]. 
Here is the great differentiator that makes DED processes suitable for large components where high BTF ratios make conventional manufacturing extremely expensive because of the material costs. Table 1 represents some examples of BTF ratios achieved for various aerospace components.

Table 1. The weight of billets, the weight of final parts, and Buy-to-Fly (BTF) ratios of aerospace components [72]

\begin{tabular}{lccc}
\hline Component & Billet (kg) & Finished product (kg) & $\begin{array}{c}\text { BTF ratio } \\
\%\end{array}$ \\
\hline Intercase & 182 & 30 & 6.1 \\
Simple duct flange 1 & 67 & 11.1 & 6 \\
Simple duct flange 2 & 67 & 7.7 & 8.7 \\
Complex duct flange 1 & 149 & 7.7 & 19.4 \\
Complex duct flange 2 & 207 & 10.3 & 20.1 \\
Large blisk & 810 & 97 & 8.4 \\
Wing rib & 657 & 18 & 37 \\
\hline
\end{tabular}

The available DED technologies can be powder-fed or wire-fed, and they also can differ with regards to the heat source utilized for melting the raw material: Electron Beam Free Form Fabrication (EBFFF), also know as Electron Beam Additive Manufacturing (EBAM); Wire and Arc Additive Manufacturing (WAAM); and Laser Metal Deposition (LMD). Each DED technology has different peculiarities, advantages, and restrictions. In following, a review of the main DED technologies is presented.

\subsubsection{Electron Beam Free Form Fabrication (EBFFF)}

The EBFFF process was first developed by The Sciaky Company of Chicago in 2004, and it was then furtherly developed in a joint venture with Boeing in 2005 [73]. It takes advantage of the Electron Beam (EB) welding technology that has been used in the aerospace since the early 1960s. Indeed, EBFFF is basically a CNC-guided EB gun that has a wire-feeder attached to it and moves across a substrate plate in order to deposit molten material layer after layer. The process takes place into a vacuum environment in order to avoid contamination and is suited to welding reactive alloys $[74,75]$.

The application of EB is preferred to the laser because of multiple operational advantages such as the scalability of the output power over a large range, and the fact that the EB can be electronically focused. These allow EBFFF technology to create parts with fine detail as well as high deposition rates. Other advantages are the intrinsic power efficiency of the process at around $90 \%$, and the very high coupling efficiency with deposited materials meaning that even very reflective ones can be deposited using this technology, as opposed to laser sources which reflectance can range from $40 \%$ to over $95 \%[74,76]$.

The Sciaky Company did numerous tests in partnership with Boeing, with the objective of qualifying the EBFFF technology for commercial aviation applications. Tensile strengths, fatigue, and fracture toughness resulted above minimum values required. Nonetheless, it was noticed that due to the vacuum environment a loss of Aluminium could appear. In turn, this would reduce the tensile strength in the horizontal plane ( $X$ and $Y$ directions) $[77,78]$.

\subsubsection{Wire + Arc Additive Manufacturing (WAAM)}

The heat source in the WAAM process is an electric arc, which can be one of the tungsten-inert-gas, metal-activegas, metal-inert-gas or plasma variants. This can be guided by a robotic arm up to 6 -axis, allowing great production flexibility and, more importantly, the possibility to create large parts as there is no such limitation as for the chamber volume [79-81]. Indeed more robots can be combined together, within the same setup, to extend the work-envelope further [82]. In addition, WAAM allows deposition rates as high as $10 \mathrm{~kg} / \mathrm{h}$ and material efficiency in the range of more than $90 \%$, resulting in a very interesting economical business case for aerospace applications [83]. These benefits come at a cost: the parts produced have lower accuracy and geometrical complexity than 
powder-fed technologies, meaning that they need further heat treatments and conventional machining in order to achieve the desired mechanical properties.

Due to the high heat generated by the arc, components manufactured by WAAM are subject to distortions and residual stress [56, 84, 85]. If distortions (both buckling and bending) are managed effectively during the build, then residual stress can be eradicated using a stress-relieving heat-treatment. In general, in line cold-work f.i. via high-pressure rolling helps reducing stress in such big parts, but in any case, a standard heat treatment is necessary for this process.

\subsubsection{Laser Metal Deposition (LMD)}

This technology uses similar hardware of WAAM but the heat source is a laser beam, and it can be either powderfeed or wire-feed as shown in Fig. 9 in various nozzle configurations. By controlling the laser power output different deposition pool sizes can be achieved [86-88]. Nonetheless, when the peak power is too high the material could reach the evaporation temperature and generate craters [58]. Generally, for a given heat amount, the pool generated from a laser is much smaller than that created with WAAM technology as the laser heat is focused in a very small area $[89,90]$.

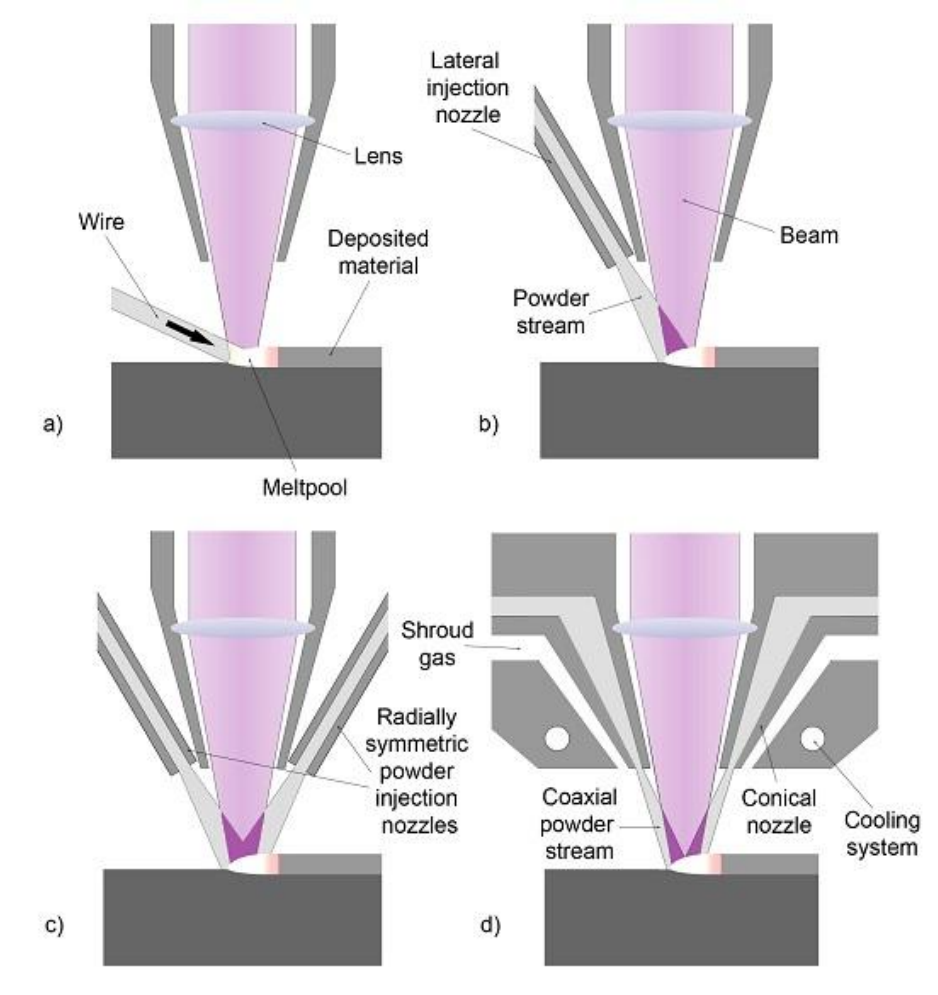

Figure 9. LMD process with different nozzle configurations [91]

Laser welding of Titanium alloys has been long used now in industrial applications such as structural components of aircraft $[89,92]$. The welding procedures used are very similar to the ones for stainless steel and aluminum, but with the addition of inert gases onto the weld pool in order to avoid oxidation of the metal [93, 94]. In fact, Titanium has increased reactivity to with other elements in the environment at high temperatures. Gas shielding is therefore of crucial importance for preserving the chemical and mechanical properties of the parts [95, 96]. Indeed, a loss of ductility could result from the embitterment of the weld region [97]. Different types of nozzles have been developed and gases such as Argon or Helium can be used for the shielding, even though it has been 
demonstrated that Helium allows a deeper material penetration [98]. It is also worth mentioning that shielding gases can remain trapped in the material after solidification and generate porosity or cracks [99, 100]. This problem does not exist when the material deposition is done in a vacuum environment, but in his case, the vacuum chamber dimensions would limit the manufacturable part size.

Although LMD has higher dimensional accuracy than WAAM, it lacks in deposition rate and material efficiency [101]. LMD is, therefore, more suitable for complex parts whereby the use of powder can help to achieve the desired geometries [102], whereas WAAM is better suited to simple geometries where lead time and cost reduction are key factors [103]. The market is showing increasing interest in wire-feed processes as Ti64 serial productions demand increased build speed and the possibility to create larger components [104, 105]. In addition, it is worth noting that LMD can be successfully used for repairing high-value components such as train wheels or turbine blades thanks to the machine flexibility and the resolution achieved using powder feedstock [106-108]. Figure 10 compares various types of metal additive manufacturing processes which applied in the aerospace industry. As can be seen, different factors in the manufacturing process, such as flexibility, surface finish, overall cost, and production volumes, are considered in this diagram. In a general view, each AM technology can be compared with the others and it seems WAAN technology can cover many of them.

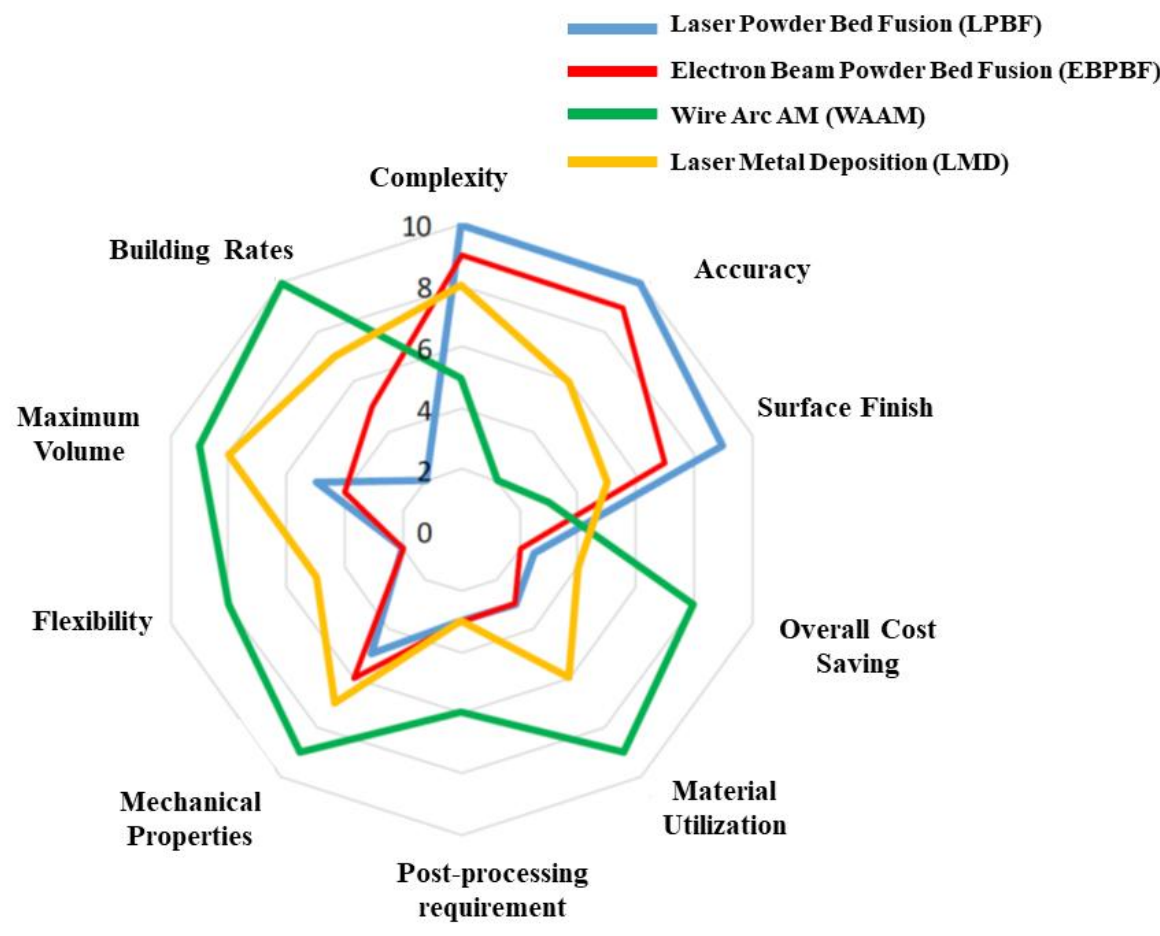

Figure 10. Comparison framework among different metal AM technologies used in the aerospace industry [109]

\section{MATERIAL ISSUES AND TESTING}

\subsection{CURRENT MATERIALS}

Aviation components have to be made of highly performing materials and need to be reliable during operations in order to assure an acceptable level of safety. The Ti-6Al-4V alloy also referred to as Ti64, is extensively used in aerospace because of its mechanical properties such as good corrosion resistance, low density, and high strength, which make Ti64 the metal with highest strength-to-weight ratio [71, 84, 110, 111]. The production of Titanium sponge, that is the pure form of the material after extraction and processing, is particularly expensive if compared to other materials: by weight, steel production is about thirty times less expensive, and that of aluminum is six times less expensive than titanium [112]. A new report from Global Market Insights Inc. shows that around 60\% of 
the worldwide demand for titanium comes from the aerospace sector, whereby the two major players Boeing and Airbus represent $90 \%$ of this demand through their commercial and military applications. The report also values the market of titanium sponge for aerospace at $\$ 1.45 \mathrm{~B}$ in 2017 and forecasts it to grow up to $\$ 1.94 \mathrm{~B}$ by 2024 thanks to an average $10 \%$ yearly increase of commercial aircraft deliveries and to the increasing share of titanium in the new generation aircraft [113].

Moreover, the increasing use of Carbon Fiber Reinforced Polymer (CFRP) materials in aerospace is driving the interest in Titanium alloys $[114,115]$. Indeed, Aluminum cannot be coupled with CFRPs as they form a galvanic cell and generate corrosion. Instead, titanium's galvanic compatibility with the carbon fibers is about one-tenth that of Aluminum. New generations of aircraft models such as the Airbus A350XWB and the Boeing 787 have CFRP share above $50 \%$ of the total used materials [116]; hence, the Titanium share is also very high at about $14 \%$ of the total. Titanium is used for main structural components and high-value assemblies that require particular strength and corrosion resistance performances: For example, in the Airbus A350 aircraft the engine pylons, most parts of the landing gears, some reinforced structural frames, and a great extent of brackets are done in Titanium [117-119].

It is worth highlighting the importance of the abovementioned BTF ratio for current materials in the aerospace industry. Since Titanium is a more expensive material than alternative metals such as stainless steel or aluminum, and because it is hard to machine with conventional technologies, the parts with current high BTF ratio would be good candidates for being produced by DED technologies. This could result in a reduction of both production lead times and material costs, and the impact would be even bigger when parts have a high functional value and leadtime becomes critical for safe and ready operations.

\subsection{POST PROCESSES}

Stress relief needs to be done after deposition and before separating the workpiece from the substrate plate [104]. The support structure that is used to anchor the part on the substrate can also be subject to high thermal stresses and can fail. This can disrupt and destabilize the build or even induce cracks in the part. In AM processes, the most common cause of residual stresses in the part is thermal gradients experienced between material deposition and solidification $[85,120]$. Residual stresses can be either on the macroscopic scale affecting dimension and geometry of the whole component or on the microscopic scale changing grains size [121, 122]. In any case, the design should take into account these misfits and avoid or control the residual stress as far as possible in order to prevent part failure in service. Components often have purposely induced residual stresses: for example, rapid cooling can induce compressive residual stress on the part surface and tensile stress in its interior, hence improving its mechanical strength [123-125]. Another example of purposely-induced residual stress is the shot peening process, which is used to induce compressive stress on the component surface $[126,127]$.

Additive Manufacturing processes by themselves are not able today to produce parts with acceptable mechanical properties and surface roughness for most application requirements $[128,129]$. For this reason, after the build is completed some post-processing task is necessary [130]. These include heat treatments for releasing the residual stresses deriving from the thermal stress; or treatments such as the Hot Isostatic Pressing, which helps reduce porosity and improve the microstructure; or processes that help to improve the surface quality. There are various post processes for AM fabricated parts such as heat treatment, hot isostatic pressing, cold rolling, laser polishing, laser shock peening which effect on surface roughness, residual stress, surface hardness, and so on. Here below the major post-processes adopted for AM components are briefly reviewed, reporting their working principle and applicability, and the effect they have on part quality.

\subsubsection{Heat treatment}

Generally, it is recommended by the international standards for multilayers material depositions to follow the production with a heat treatment in order to increase surface quality, reduce internal welding stresses, and close micro cracks in the components [131-133]. The stress relief heat treatment shall be under a protective 
atmosphere of inert gas or vacuum so that chemical reaction is avoided at high temperature [134]. For example, DIN 17869 standard provides some information for the heat treatment method to relief welding stresses of multilayer welded component. Also, the DIN 65083 standard suggests particular parameters for the heat treatment of titanium and its alloys. According to this standard, the treatment temperature should be kept at $675^{\circ} \mathrm{C}$ for a 60 minutes period, after which the cooling rate is recommended at less than $2.5^{\circ} \mathrm{K} / \mathrm{min}$ in order to maintain the achieved microstructure $[34,135]$.

\subsubsection{Laser processing}

Laser processes is an applicable and flexible approach to improve the surface of additively manufactured products. During this process, the metal surface can be melted and the relocation during the liquid phase can make a smoother surface [136]. Ablation method is the other process using a laser that can evaporate the materials and the defected layer can be removed by this way from the 3D manufactured part. Overall, the laser processing of AM parts can improve considerably the roughness, wear resistance, microstructure, and porosity based on various research reports [137-139]. Cernasejus et al. applied the laser processing using Nd: YAG laser for additively fabricated stainless-steel parts. They investigated the effect of the laser parameters, including laser power, scan speed, and the number of passes, on the surface quality of AM parts. In this study, they found laser process can diminish the roughness of the fabricated parts up to $41 \%$ and make a significant improvement in wear resistance using higher laser power and slowest laser speed with 4 laser passes. This study demonstrated the positive influence of laser processing for improving the surface quality of steel 3D printed products [136].

\subsubsection{Hot Isostatic Pressing (HIP)}

The HIP process is commonly used for AM-produced parts just after the build. It is recommended to do a heat treatment after HIP in order to get the maximize the beneficial effect of the treatment [140-142]. It consists of the application of a very large pressure to the part in order to close any porosity remaining from the process. Normally a pressure of 1000 bar is used, but for particular applications, the pressure could be increased to 2000 bar. Concurrently, the temperature is kept high too. A common set-up is $920^{\circ} \mathrm{C}$, but in this case, too, depending on the application the temperature could be raised up to $2000^{\circ} \mathrm{C}$ [143]. The high pressure generates a collapse of the pores by plastic deformation and brings the surfaces of the pores to contact. The condition of high temperature and pressure for a sufficient time allows creep and diffusion mechanisms to bond definitively the material and close the pores. Because the high pressure is provided into the chamber through injection of an inert gas such as Argon, negative effects on the surface are avoided and quality is maintained. Such process results very beneficially for the internal quality of the part [144] and no particular negative counter-effects have been found in the literature.

Although AM processes are capable to produce high-density products above $99 \%$, micro-cracks or porosity could still exist and could affect fatigue behavior in service $[145,146]$. Therefore, it is always suggested the use of HIP after production. Indeed, it was demonstrated that for AM-produced parts, HIP almost completely eliminates porosity and densities above $99.99 \%$ can be achieved [147]. Table 2 illustrates the benefits of the HIP on Titanium alloy (Grade 5) with six specimens were produced by EBM in Ti64 and were placed on the build platform in a different orientation. One vertical and another horizontal were tested for porosity without using HIP while the other four samples underwent HIP at 1000 bar and $920^{\circ} \mathrm{C}$. As it is visible in the result reported in the table, the porosity, which was already very low without HIP, was practically canceled after HIP. Moreover, it is worth mentioning that HIP increases the columnar grain size and thickness of the alpha phase in the build direction. After HIP, the alpha phase concentration is changed and the number of dislocations too. This improves consistently the material ductility besides fatigue life improvement [147].

Table 2. Mean values of porosity and bulk material with and without HIP [147]

\begin{tabular}{lcc}
\hline Build cycle and orientation & Porosity (\%) & Bulk material (\%) \\
\hline BPO-XY, No HIP & 0.0754 & 99.9246 \\
BPO-XZ, No HIP & 0.3267 & 99.6733
\end{tabular}




\begin{tabular}{lll} 
BP1-XY, HIP & 0.0002 & 99,9998 \\
BP1-XZ, HIP & 0.0033 & 99.8867 \\
BP2-XY, HIP & 0.0028 & 99.9972 \\
BP2-XZ, HIP & 0.0045 & 99.9955 \\
\hline
\end{tabular}

\subsubsection{Cold rolling}

The post-processing of DED processes cannot be the same as for PBF-produced parts due to the large dimensions achievable with DED. Indeed, due to design requirements, the ratio between length and width of the part can be one order of magnitude higher than for PBF processes. Therefore, thermally induced residual stresses could possibly generate deformations that would compromise the geometry and functionality. Cold work via rolling can be applied to the part directly after material deposition in order to improve the microstructure and reduce porosity $[103,148]$. The process benefits are very similar to those achieved by shot peening, where the small spheres hitting the surface reduce tensile stresses, and sometimes compressive stresses are generated instead. On the other hand, rolling can generate compressive stress continuously and the plastic deformation would cover the entire cross section of the weld [149].

In order to prove the benefits of cold rolling for AM-manufactured large parts, Colegrove et al. made some experimental tests using two different types of roller [150]: one profiled with a $3.6 \mathrm{~mm}$ radius and another one with a $10 * 5.2 \mathrm{~mm}$ slot that allows maintaining the lateral sides of the deposited material in place. The representation of the rollers used in the experiment is shown below (Fig.11). Without rolling, the specimens 490 $\mathrm{mm}$ long resulted in high longitudinal deformations and $7 \mathrm{~mm}$ upward bow on each side. In-line rolling did not result in significant distortion reduction because of the high temperature of the material. On the other hand, when rolling was done after reaching a temperature of $50^{\circ} \mathrm{C}$ and after each layer or after every four layers, the deformation was significantly reduced linearly with the applied load. In addition, this picture shows that rolling loads with the slotted roller allows achieving deposition efficiency of almost $100 \%$, which is the ratio between the effective wall width after machining and the total deposited wall width. On the other hand, higher loads generate plastic collapse and thus lower deposition efficiency [151]. For what concerns residual stresses on the longitudinal deposition direction: rolling reduced tension stress from $650 \mathrm{MPa}$ to $250 \mathrm{MPa}$ on the interface, and the stress is spread over the whole section rather than on the surface only.

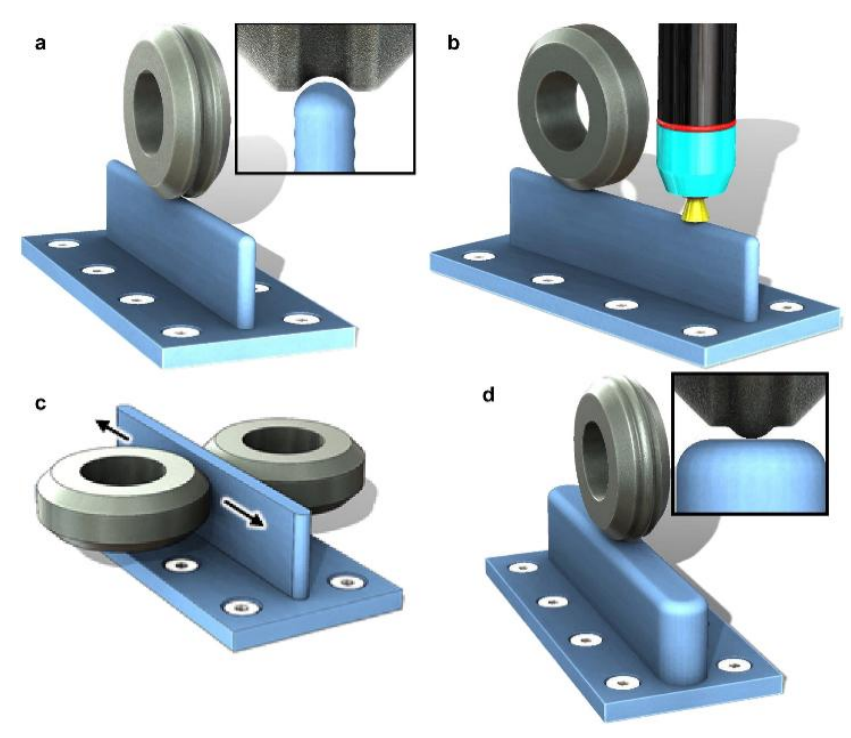


Figure 11. Various rolling methods: (a) vertical and (b) in-situ rolling; (c) pinch rolling-using two rollers on both sides of the profile; and (d) rolling for thick sections and intersections with an inverted profiled roller [150].

It can be concluded that, following experiments of high-pressure cold rolling during fabrication of large components using WAAM, this system can considerably reduce peak residual stresses and spread the effect over the cross-section of the deposited material $[152,153]$. The resulting distortion in the longitudinal direction is also reduced, whereby a slotted roller is more effective maximizing the deposition efficiency too. One important consideration is that rolling straight after deposition does not provide effective benefits for the mechanical properties, whereas it is best to apply to roll after every layer or every fourth layer.

\subsection{MATERIAL TESTING}

Because of the complex geometries that AM processes are capable of building, one of the great challenges for their adoption is quality control of the produced components [154, 155]. Standard measurements systems that are commonly used for conventionally manufactured parts are oftentimes not enough for AM applications. Indeed, some designs might include internal cavities that are not visible from the exterior or even spatially variable geometries. In the following paragraphs, in the first place, a review of the tests, both destructive and nondestructive (NDT) that are commonly used for AM applications is done. Secondly, the challenge for developing insitu monitoring for AM processes is examined and the state-of-the-art examples of these systems are shown as well.

\subsubsection{Destructive and non-destructive testing}

A number of tests shall be performed on the AM-produced components in order to assess their mechanical properties, to confirm compliance with fatigue limit requirements, to confirm material's chemical composition or its microstructure. Some critical are listed below based on the various analysis.

\section{Chemical analysis of material:}

- Analysis of titanium alloy by direct current plasma and inductively coupled plasma atomic emission (ASTM E2371)

- Determination of oxygen and nitrogen content into titanium alloy using inert gas fusion (ASTM E1409)

- Determination of hydrogen content into titanium alloy using inert gas fusion thermal conductivity or by infrared detection (ASTM E1447)

- Determination of carbon content through combustion analysis (ASTM E1941)

\section{Microstructure assessment:}

- Determine the grain size of the alloy using specimens placed in the build bed with the components (ASTM E112)

- Determine surface contamination (EN 2003-4)

- Assess metallographic structure through micro-etching (ASTM E407)

\section{Static mechanical properties assessment:}

- Tension testing for measuring Yield Stress (YS), Ultimate Tensile Stress (UTS), Young Modulus (E), and elongation (A). (ASTM E8M)

- Tensile testing at room temperature (ISO 6892)

Fatigue behavior assessment:

- Axial fatigue test with constant amplitude and controlled force (ASTM E466)

- Low-cycle fatigue test with the controlled strain (ASTM E606)

- Crack growth rate measurement (ASTM E647)

Hardness and toughness assessment: 
- Standard guide for evaluating mechanical properties of metal materials made via additive manufacturing processes including Brinell Hardness [E10], Rockwell Hardness [E18], Fracture Toughness[E1820], so on. (ASTM F3122 - 14)

In addition to the abovementioned tests, a number of non-destructive testing (NDT) can be performed on the part in order to assess its quality without damaging it permanently. Basic procedures include dimensional and tolerance analysis with the use of white light or laser system, or visual inspection of the part to control geometrical integrity and absence of superficial macro-cracks. One of them is computerized tomography scanning (CTS), for detecting deep defects that might be embedded in the material during solidification [156]. Defects visible might be pores, material not completely fused, or impurities. This system scans the object in many different in various positions by rotating it, and then the software re-composes the scans to build the 3D image of the part. The CTS is also useful for measuring internal features that would not be accessible otherwise. The only limitation of CTS is the minimum size detectable of $27 \mu \mathrm{m}$. Also, Internal X-Ray radiography could also be used to detect discontinuities, but this system is only limited to thin plates $[157,158]$. The other method is Dye-penetrant inspection (DPT) which can help detect micro-cracks on the surface. It is necessary to rework and reduce the surface roughness before applying the penetrant. Indeed, the as-built roughness of AM parts is at least $20 \mu \mathrm{m}$, which means that without pre-emptive surface rework any crack would not be visible [147, 159].

\subsubsection{In-situ process control}

It is true that AM allows to produce new and more complex designs and shapes compared to conventional manufacturing techniques, but it is also true that complex geometries pose new challenges to metrology and quality control. The challenge comes from the fact that AM creates both the geometry and the material simultaneously, defining its internal microstructure during the deposition. The organic geometries possible with AM need greater data processing power in order to be analyzed, together with innovative methodologies [5]. The problem becomes considerably more difficult to deal with when lattice structures, which most of the times are internal to the component, need to be measured.

As mentioned, AM allows creating functionally graded materials where density changes spatially in the same component, or where the material alloy deposited in gradually but continuously modified during the deposition. One of the biggest barriers to the widespread adoption of AM in the industry is the lack of adequate process control systems [160]. Indeed, the development and adoption of in-situ process monitoring systems with a direct feedback loop would incentivize the integration of AM processes in the industry [161, 162]. This is even more valid in strictly regulated sectors such as aerospace and medical industries. Non-destructive testing (NDT) for metallic AM parts is not yet a standardized practice, but it has recently been introduced into the main agenda of ASTM and the International Standardization Organization (ISO) [163].

Some common discontinuities that have been recognized in PBF processes are the voids (or pores) that can appear either within the layers or between them. The pores may derive from operational settings of the SLM/EBM machines such as heat power. Indeed, low power may not be able to melt all the powder particles or the previous layer in order to create a strong bond [164]. The un-melted grains have an important impact in void formation, and the same effect can be noticed with the too high-power setting. In this case, the melt pool might sustain turbulence and part of the material could evaporate leaving gas bubbles inside the bulk material [165].

\subsubsection{PBF Process Monitoring}

A machine manufacturer called Concept Laser (a subsidiary of GE Additive) provides one solution allowing inspection of SLM-made parts with in-line camera systems. Figure 12 represents a schematic of the monitoring process. The system consists of a high-speed camera and a photodiode being mounted close to the laser source: the diode measures the mean values of the electromagnetic radiation produced by the material melted by the laser; at the same time, the camera records the dimension of the pool [166]. The information provided by the camera and the photodiode would be used in close-loop with the machine and would help stabilize the process and limit risks of over-melting the material. 


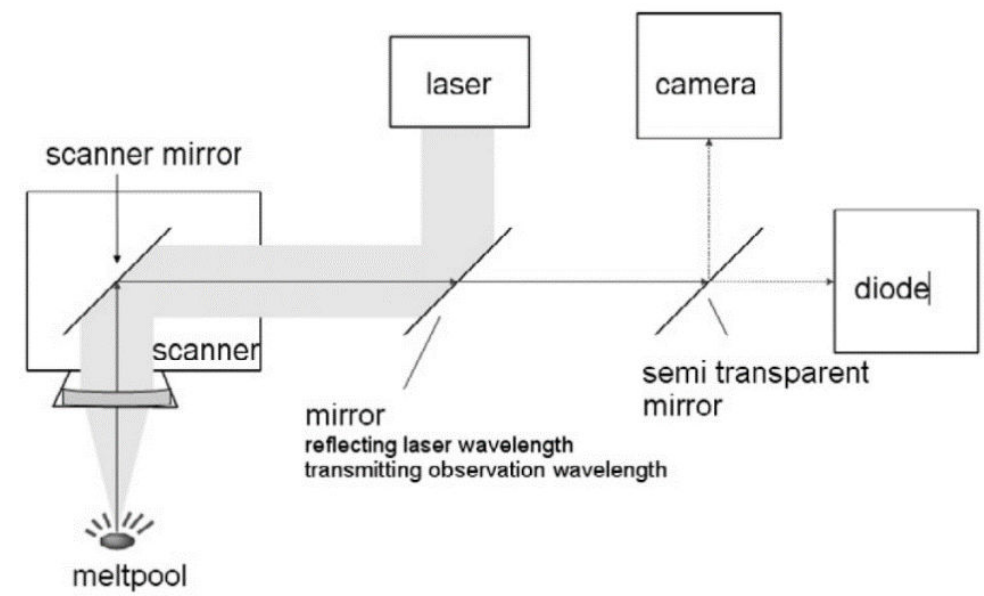

Figure 12. A schematic of the positions of laser and camera in PBF monitoring [166]

Rather than monitoring melt-pool itself, another interesting use of high-speed cameras was done to control the correct powder deposition after each roller passage [154]. Indeed, some inconsistent solidification of material from the previously deposited layer could damage the rollerblade. This would clearly affect the following layers either by creating V-shaped engraved stripes or allowing too much powder to be deposited in certain areas [167]. For what concerns the in-line quality control of EBM-produced parts, there are a number of additional difficulties due to the equipment architecture itself. Firstly, the chamber being in a vacuum atmosphere does limit any type of installation of cameras or other equipment in it. Secondly, the magnetic coils that deflect the electron beam do not allow installing co-axial cameras as metal evaporation might cause metallization of the viewing screen [163].

One monitoring system that seems possible today on EBM machines is an Infrared (IR) camera that allows recording the surface temperature of each layer just after its deposition [168]. This also would help to identify discontinuities due to over-melting, and the information sent to a control system could be directly fed back to the machine computer in order to regulate the output power [169].

\subsubsection{DED Process Monitoring}

The difference with the previously discussed systems for PBF relies on the fact that the material is being deposited concurrently with the heat source. Two main types of defects can be noticed in DED processes with powder-feed laser-heated systems: porosity in the material and superficial cracks. Similarly, to what has been said for PBF processes, shielding gas might remain trapped into the material powder thus generating pores. This is especially true when excessive powder flow rates are fed into the melt pool. Another issue causing porosity derives from low energy density, which is not capable of melting the entire quantity of powder that is fed. The second problem is crack generation on the surface: this is arguably due to the material characteristics and its thermal expansion rates [163]. Pyrometry data can be captured and analyzed in order to predict the size of the melt pool. This information can be then fed back to the computing system in order to modify deposition parameters and stabilize the process.

Another possible closed-loop monitoring system for powder-fed machines is to use IR cameras in order to record material discontinuities in the deposited layer. Doubling this solution, it can also be possible to achieve feedback control on both deposition energy and layer height [170]. Although the wire-fed DED processes have the material delivered differently on the melting spot, the type of discontinuities found in the material are of the same type of those found on powder-fed DED. Therefore, the same type of monitoring systems is studied and developed, such as IR camera systems. A promising control system developed by Liu et al. uses a spectrometer for detecting emissions generated by the plasma plume during deposition. The analysis results from the spectrometer are then compared with the clad quality (known a priori) in order to determine properties such as surface quality, 
microstructure, and hardness. The spectrometer is assisted by a high-speed camera and a green laser constantly monitoring the melt-pool as shown in Fig. 13 [171].

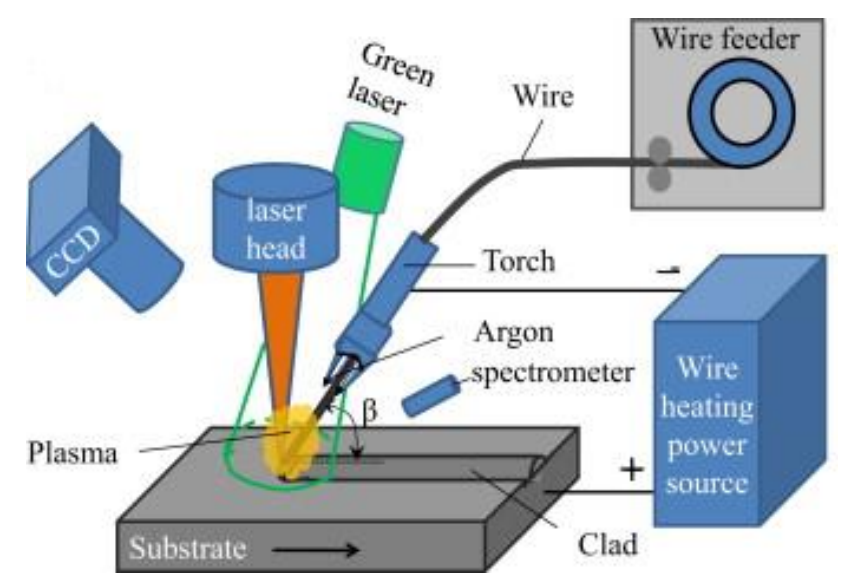

Figure 13. Set-up scheme for laser hot-wire deposition assisting a high-speed camera and a green laser [172]

To conclude, it seems that as of today there is no available in-line monitoring system capable of being automatically connected with the AM machine parameters and changing them as necessary in a closed-loop system. Nevertheless, a number of studies have brought some advances in the subject, whereby Infrared cameras or thermal metrology are already capable of gathering interesting data from the job and thus improve the machine setting. Indeed, these monitoring processes are not at all autonomous yet, and they still rely on a priori information provided to them, such as the type of deformation we are looking for, or the causes of such misfit. In other words, these systems are useful to better understanding the process itself.

\section{DESIGN FOR AM PROCESSES}

Nowadays, in the manufacturing industry, it is important to increase the efficiency of production systems and reduce costs in order to stay competitive in the business [173]. Production lead time has become a key indicator for competitiveness as business models require a faster time to consumer and levels of customization have reached a historical maximum [174]. One of the design strategies, in order to effectively reduce lead time, is to reduce the part count. indeed, this would have a direct effect on assembly operations, inventory, and logistics, providing both operational and managerial simplifications. Just to mention the fact that no specific tooling, fasteners, jigs, and fixtures would be required anymore for the assembly operations gives a good idea of the simplification extent, apart of the secondary benefit of providing enhanced agility to the system. in case a product re-design is needed, not all the system has to be re-thought but a simple CAD modification would be sufficient [175-178].

Although consolidating multiple parts into a single design might seem a good idea for simplifying the whole production chain, it comes naturally with some consistent drawbacks. In fact, the consolidated part would have a much higher complexity than the original constituent components of the assembly, requiring reliable manufacturing processes that are able to assure consistent mechanical properties, along with more sophisticated inspection techniques for quality control both in production and in service. With such opportunities, the re-design would not only be limited to producing the whole assembly in one single piece, but it would need a re-thinking of the assembly's functionality and dimensional requirements such as an interface with other assemblies and surface finishing, and the material volume needed for assuring and maximizing the mechanical properties. Thompson et Al. 
define three levels of opportunities and related complexities for AM design: part level, material level, and product level [5]. In following, these factors are discussed with more details.

\subsection{PART LEVEL AND ASSOCIATED MACRO SCALE COMPLEXITY}

On the market, it is now possible to find AM technologies allowing printing a variety of materials from polymers, metals, ceramic, and even foods. Some processes even allow producing parts already colored by adding pigments to the raw materials or by activating them during the process. The ability to create freeform geometries, and thus parts that are difficult or sometimes impossible to produce by conventional manufacturing, appeals a lot of industrial and fashion designers, as well as interior designers for high-end furniture and lighting fittings [179]. Table 3 categorizes the applications, advantages, and challenges of the AM process based on various groups of materials mainly for the aerospace industry [180].

Table 3. Some applications, benefits, and challenges of the principal materials for AM [180].

\begin{tabular}{|c|c|c|c|}
\hline Materials & Main applications & Benefits & Challenges \\
\hline $\begin{array}{l}\text { Metals and } \\
\text { alloys }\end{array}$ & $\begin{array}{l}\text { - Aerospace and Automotive } \\
\text { Military } \\
\text { - Biomedical }\end{array}$ & $\begin{array}{l}\text { - Multifunctional optimization } \\
\text { - Mass customization } \\
\text { - Reduced material waste } \\
\text { - Fewer assembly components } \\
\text { - Possibility to repair damaged } \\
\text { or worn metal parts }\end{array}$ & $\begin{array}{l}\text { - Limited selection of alloys } \\
\text { - Dimensional inaccuracy and poor surface } \\
\text { finish } \\
\text { - Post-processing may be required (machining, } \\
\text { heat treatment or chemical etching) }\end{array}$ \\
\hline $\begin{array}{l}\text { Polymers and } \\
\text { composites }\end{array}$ & $\begin{array}{l}\text { - Aerospace and Automotive } \\
\text { - Sports } \\
\text { - Medical } \\
\text { - Architecture } \\
\text { - Toys } \\
\text { - Biomedical }\end{array}$ & $\begin{array}{l}\text { - Fast prototyping } \\
\text { - Cost-effective } \\
\text { - Complex structures } \\
\text { - Mass customization }\end{array}$ & $\begin{array}{l}\text { - Weak mechanical properties } \\
\text { - Limited selection of polymers and } \\
\text { reinforcements } \\
\text { - Anisotropic mechanical properties (especially } \\
\text { in fiber-reinforced composites) }\end{array}$ \\
\hline Ceramics & $\begin{array}{l}\text { - Biomedical } \\
\text { - Aerospace and Automotive } \\
\text { - Chemical industries }\end{array}$ & $\begin{array}{l}\text { - Controlling porosity of lattices } \\
\text { - Printing complex structures } \\
\text { and scaffolds for human body } \\
\text { organs } \\
\text { - Reduced fabrication time } \\
\text { - Better control of composition } \\
\text { and microstructure }\end{array}$ & $\begin{array}{l}\text { - Limited selection of 3D-printable ceramics } \\
\text { - Dimensional inaccuracy and poor surface } \\
\text { finish } \\
\text { - Post-processing (e.g. sintering) may be } \\
\text { required }\end{array}$ \\
\hline
\end{tabular}

According to Thompson et al. [5], the major industrial interest for AM is driven by the parts' increased functionality and performance enabled by complex geometries. One of the most studied applications is with no doubt conformal cooling, where channels follow the same shape of the part [181, 182]. Research shows that using conformal cooling strongly improves the heat transfer in the part, increases its efficiency and quality, and reduces cycle times as well as maintenance intervals. All the mentioned benefits generate important cost savings over the life of the part $[183,184]$. Other remarkable examples of complex geometries in the literature include integrated wiring channels and air tubes for robots [185], or a water redistribution manifold [186] where the optimized paths of fluid channels allowed a $90 \%$ reduction of vibrations caused by turbulence.

In the aerospace sector, a very valuable benefit of using AM is to create topology-optimized parts $[187,188]$. This consists in identifying where to put material exactly in order to achieve the desired set of mechanical properties (e.g. stiffness for given loads, uniform stress) while reducing the part's weight and material employed. Such design freedom may allow overcoming design limitations such as uniform wall thickness and sharp corners. In other words, AM could allow rethinking designs so that material is put where is needed only and produce parts with theoretically no restriction on geometric complexity and no need of specific tooling [189].

Meyer and Tomlin provided a groundbreaking example of topology optimization. They did a business case for redesigning an aerospace bracket that is used in the Airbus A320 nacelles hinges [190]. The nacelles are the cowls 
of the engines and are hinged on the top side on the engine pylon so that they can be opened for maintenance and inspection. The objective of the optimization was, in that case, to minimize the weight maintaining the same functionalities of the part. The original part was manufactured with HC101 steel and was replaced with Ti64 additively manufactured through the SLM process. The design had some constraints driving the functional requirements, such as the maximum displacement along the hinge, the maximum yield stress was limited at $1,000 \mathrm{MPa}$, and the fatigue limit kept at $350 \mathrm{MPa}$ for 400,000 cycles. The optimization loop below shows the redesigned part with a completely new geometry that would be probably not possible to produce by conventional methods (Fig.14) [190, 191]. The stress in the new part resulted to be more homogeneous and the weight reduction achieved was quite impressively positive. The original part weight $918 \mathrm{~g}$, about $32 \%$ of it was reduced because of the material change while another $32 \%$ reduction was due to the design optimization. Altogether, the benefits resulted in the new part weighting $326 \mathrm{~g}$ while maintaining the mechanical properties unchanged.

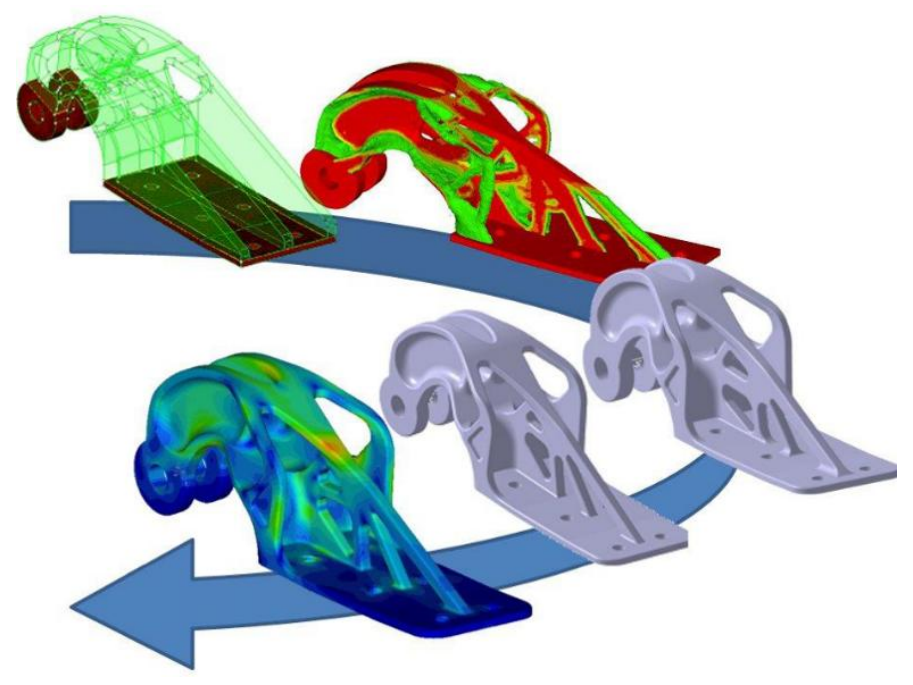

Figure 14. Optimization loop of Airbus A320 nacelle hinge bracket [190]

It is also worth mentioning the AM capability of producing highly customized products and even bespoke ones $[192,193]$. Today AM is widely used in the medical and dental sector for biomedical implants and prostheses, or for creating bespoke furniture [194, 195]. Nevertheless, in the future highly customized parts could be introduced in commercial aircraft too, notably for cabin components such as decorative parts that are customized by each airline with their unique designs [196].

\subsection{OPPORTUNITIES AT MATERIAL LEVEL}

The process of Additive Manufacturing creates the material at the same time as geometry. This allows modifying or combining different materials, for example by mixing different powders or by alternating them [22]. Moreover, with the use of specific process parameters and build orientations, it is possible to enhance the mechanical properties of the object by controlling the material properties such as its microstructure and its porosity [197].

As it has already been discussed earlier, in-situ post-processing can be used to improve material properties while layering [163]. High pressure rolling could be done after each deposition passage in order to refine the part's microstructure. Alternatively, customized surface textures and porosity could help achieve specific functionalities, such as improved surface fixation of medical implants $[198,199]$. Variable porosity is also achievable through some AM processes and allows generating functionally graded components. 
Another extremely interesting and promising opportunity deriving from AM design freedom is no doubt its ability to create lattice structures at micro-level, which is in the range of $0.1-10 \mathrm{~mm}$ [40]. These structures are defined as interconnected networks of struts and plates and can replace solid material for improving performance. Indeed, lattice structures have a higher stiffness to weight ratio than the bulk material that it is originally made of [200]. These structures can be homogeneous or heterogeneous, in which the thickness of struts is variable, and the orientation of lattice cell units can change according to load and stiffness requirements. Heterogeneous lattice structures are more complex to manufacture but they maximize performance benefits. In the aerospace, lattice structures are widely utilized also with other materials. For example, most of the panels in the cabin are made with sandwich structures in composite materials, where a lattice structure is included between two flat layers. This is a commonly used way to save weight in an aircraft, namely reducing the material volume used for achieving the same mechanical properties [201].

\subsection{PRODUCT DESIGN FREEDOM: PART CONSOLIDATION}

Thanks to the ability to produce complex geometries, AM could reduce the assembly's components by consolidating the design [202]. It has advantages such as a reduction in the assembly time because of the reduced number of components and thus lower inventory kept for sub-assemblies due to the simplified supply chain. In addition, having fewer assembly steps in the process result in fewer quality inspections and quality escapes too $[203,204]$. Consolidation may also have a beneficial effect on parts reliability, as the number of parts coupling is reduced, and these are quite often the initiation of failures [196]. One of the most successful examples of parts consolidation, at least in the aerospace sector, is the fuel nozzle of the General Electric CFM LEAP aircraft engine. The assembly was originally made of 20 parts and thanks to the use of AM it was reduced to one single component. The consolidation resulting collateral benefits were a $25 \%$ weight reduction and an estimated five times higher part life [205].

Nevertheless, the overall impact of the design change should be analyzed over the entire life cycle of the for not only the manufacturing phase, and a more comprehensive study should include the part service and maintenance, inventory and logistics, and so on. One methodology for parts consolidation is proposed by Yang et Eilg[1189Tlaedniitiodhepattifellytmepreodesigech iprocess are the initial CAD design, of course, the functional requirements (FRs) and the Performance Requirements (PRs). The FRs define what the components are supposed to do, whereas the PRs identify how efficiently the functions are achieved by the design. During the function integration step of this re-design process, the functional surfaces and volumes need to be identified. As a simplistic example, in a wing, the surface has the main function of providing lift while the internal volume can be optimized for weight efficiency. In many components, the volume can be seen as a mean for connecting functional surfaces. In these cases, the volume can be optimized by replacing bulk material with additively manufactured lattice structures. 


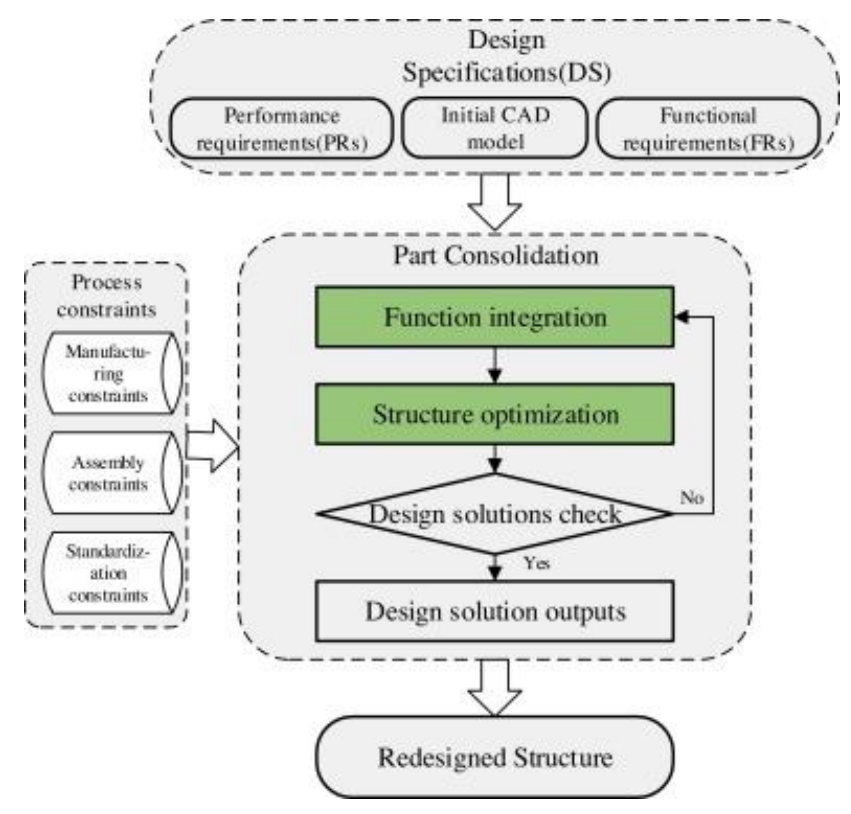

Figure 15. Methodology for part consolidation [189]

Knofius et al. [205] argue that it is not evident whether recreating an existing assembly by consolidating all its parts into a single component or fewer components would increase the overall value of the assembly. Firstly, because in case of failure the consolidated part would need to be replaced while the assembled one could have one of its parts replaced. This would possibly create additional costs due to the higher value of the spare parts inventory. In addition, the use of standardized low-level components would not be a possibility anymore and neither the practice of pooling inventory stocks. It becomes now clear that the evaluation and the decision perimeter must be widened up to include the spare market and the inventory costs for keeping spares.

It can be said that part consolidation has inevitable advantages for it reduces the parts count and thus the assembly operations. Nevertheless, the re-design process heavily relies on the designer's experience on functional requirements of the assembly. It is also well understood that the process should involve an analysis of functional surfaces and volumes, and a successive definition of performance goals which drives the optimization [189].

\subsection{DESIGN CONSTRAINTS}

In the previous section, we have seen some of the opportunities in product design that could be enabled in the present and future by AM technologies. Nevertheless, because most of the processes and their applications are still in the proof-of-concept phase, it is important to evaluate the design constraints as well as product through-life requirements. These aspects could be blocking points for a large-scale commercial diffusion of AM technologies. Firstly, the digital model must be of higher quality than those for conventional machining. Because during AM parts production there is no human intervention, a set of comprehensive information such as the tool path, support material, colors, and tolerances before the model is converted into machine instructions. Here is a big challenge: CAD programs available on the market are mostly based on parametric NURBS systems, which work well with geometries used in conventional manufacturing, but are not suited for the complex and freeform geometries used in AM.

Moreover, the above-mentioned CAD systems are unable to create lattice structures or material differences and variations within the product. One of the methods used to overcome this limitation is 3D scanning a physical object (an existing product or a clay model) [206]. The scan generates a geometry based on triangulated data that can then be further refined. It is clear that digital modeling is a key part of the AM process and a lot of the overall 
production effort via $\mathrm{AM}$ technologies resides in product engineering. Extensive research is being done to overcome current software constraints and to increase capabilities by including material information as well as the final products' functionalities requirements [5].

Another design aspect that needs to be addressed during the product-modeling phase, and that could be considered as a limitation of AM technologies, is the strong dependency of the final properties on directionality and building orientation. The discretization of the part into layers creates itself a roughness that is typical of additive manufactured components. Boundaries between layers could potentially initiate cracks or other failures if left as-is, and generally, the resulting properties are anisotropic. One way of improving material properties is of course post-processing, whereby an additional manufacturing step is added to improve the build quality. A review of some common post-processes was done in section 3.2.

Another way of reducing material anisotropy is to change the orientation of the component in its printing bed during the modeling phase [207]. Indeed, because of the layer's deposition, a step-effect is visible on the sides of the build. The orientation of the part can also help to improve the strength of the build during the process [208]. Indeed, as opposed to conventional processes, AM parts are in their weakest phase at the beginning of their process and therefore gravitational loads, mechanical and thermal stresses could negatively affect the artifact quality. Other than the orientation, designers can opt for self-supporting structure designs or in most cases for additional support structures that are taken away after manufacturing [209]. The optimization is needed in order to avoid the build to be fractured or to collapse, and for metal components, support structures are also critical for heat management and to reduce heat-related stresses.

It is likely that any kind of support strategy would increase the manufacturing cost, but this is strictly necessary in order to achieve an acceptable design with required properties. For example, the cantilever beams showed in Fig. 16 which are topology-optimized and produced by SLM, show three possible approaches for dealing with overhang structures where the weight of the part itself could cause structural failure [210]. Section (a) shows a strategy with columnar support that would be cut away after the process is completed. Section (b) is the part produced without support failed during the build in the two spots identified by the arrows. This is because AM parts are stronger at the end of the process, when the part is completed, whereas during production the weight of the material itself could damage the build. Lastly, Section (c) represents the same cantilever produced using a self-supporting design. The cantilever case result is that the self-supporting beam took $50 \%$ less time to print and about $20 \%$ more print material than the design with columnar support. In addition, no support material for the additional structure was required with the advantage of simpler post-processing.
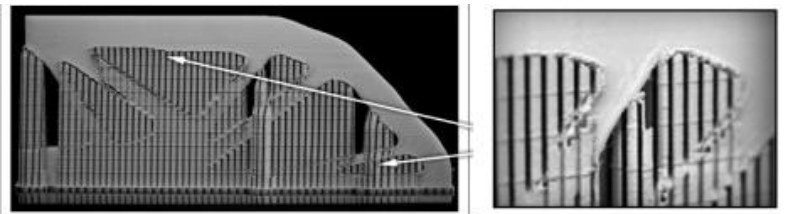

(a)
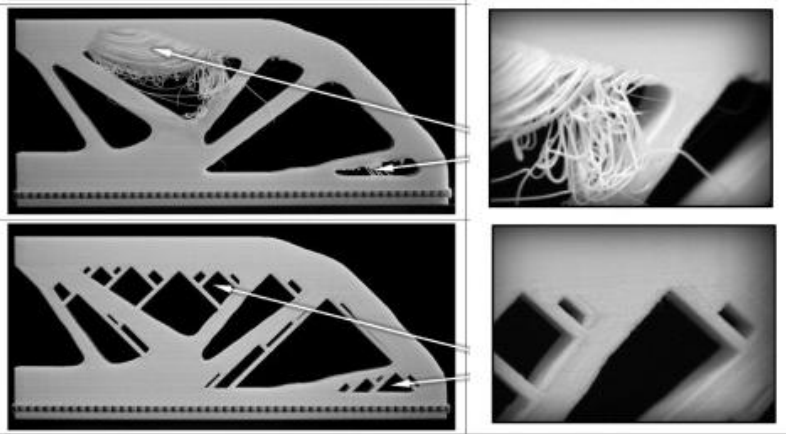

(b)

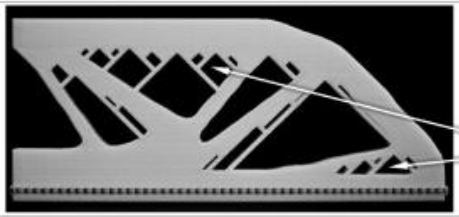

(c) 
Figure 16. Closeup of build support strategies, (a) successful build with support, (b) failed to build with no support, (c) successful build with self-supporting structure [210].

\section{AM COST}

Cost evaluation plays a key role when assessing the feasibility of including AM systems in a production environment $[184,211]$. Indeed, the cost of the final product is a key variable that cannot be neglected as business performances usually have a strong dependence from it. Therefore, product cost estimation should be as accurate as possible in order to predict better the margins that a company can make out of manufacturing [212]. Product cost estimation is a widely studied matter because of its importance, and many cost modeling techniques can be found in the literature $[213,214]$. Nevertheless, because of the fact, the AM technologies have only been introduced recently in the market, there is not enough historical data that can be used for models, hence not all the models can be successfully utilized with AM.

\subsection{PRODUCT COST MODELS}

When a precise cost model is available, it is possible to compare different AM technologies among them or to make comparisons with conventional manufacturing processes. As cost is one of the main variables when evaluating a business case, it is important to include as many details as possible so to reflect reality at best. Some of the commonly used cost modeling techniques are shown below.

\subsubsection{Analogical techniques}

This type of cost-modeling techniques, also known as regression analysis, making use of historical data from past designs in order to establish the cost structure of a new product [215]. Changes in the model parameters need to be done as soon as the product specifications change. In order to maximize the accuracy of such a model, it is preferable to prioritize and weigh the impact of each feature on the model. This approach is preferred in the early stages of a design or in prototyping. In the case of AM, this approach might consider, for example, specific surface quality requirements as a process constraint and so associating a cost to the post-processing operation. This system works well with independent variables that have a linear relationship with their cost associated [216].

In the case of the non-linear relationship between the variables and their costs, Artificial Intelligence (Al) is more suitable. Artificial Neural Networks (ANN) is a system capable of determining with success multi-relations and nonlinear relations of variables [217]. Al is extremely helpful especially in the design of early phases, as it can achieve accurate results even with poor background information. Indeed, the ANN system is simulating the logical and sequential process of human experts when identifying variables and defining their relationship with the cost structure [60].

\subsubsection{Analytical techniques}

Activity Based Costing $(A B C)$ is the technique most commonly used for AM processes in the literature [1]. It allocates a direct cost to each operation performed, and distributes the overhead costs over the operations, on a pro-rata basis. It seems to be very helpful in case of large fixed costs, for example, related to the machine. Operation Based Costing is quite similar in the principle to $A B C$, but it needs a much larger set of information regarding the process [218]. In fact, all operations involved in the process need to be understood, and their time measured including set-up and changeover times. Therefore, this approach is more suitable for the final phase of manufacturing when most of the information are known [60]. Feature-Based Costing associates some design features to a cost associated with it to build up a comprehensive cost structure [219]. Since this technique strongly relies on the design complexity in order to define its cost, it is not suited to AM. 


\subsection{AM COST MODEL}

As AM is a capital-intensive process - meaning that a large investment is needed to acquire the machine in the first place - it makes sense to spread such fix cost over the utilization period. Therefore, in literature, it is common to find AM cost models based on the subdivision of direct and indirect costs, as follows $[5,60,220]$ :

\section{Direct costs:}

- The raw material for part and support structure

- Energy consumption including machine warm-up

\section{Indirect costs:}

- Machine purchase, depreciation, and maintenance

- Labor cost including setup and post-processing

- Production and administrative overheads

Where the indirect costs are expressed in the hourly rate and depend on the annual machine operating rate and the equipment's depreciation. The entirety of the above-listed costs are the so-called "well-structured" costs, namely those costs necessary for manufacturing the part. It is worth noting that such cost structure does not take into account any costs related to building failure, raw material inventory, or logistics, namely the "ill-structured" costs. In addition, and most importantly, such a structure fails to consider the efficiency of filling the machine build plate [221].

In fact, in order to achieve a more realistic model, it is necessary to introduce a variable related to the build volume packing efficiency. The volume can be occupied by the same parts or by completely unrelated parts. As it is understood, the AM machine operational efficiency would not depend on the items produced and their complexity, but only by their volume. Indeed, the mentioned variable could be defined as the ratio of the occupied build volume floor voxels and those available. The labor cost mentioned above includes post-processing as these tasks are needed to achieve a final product with the desired technical requirements, and full cost analysis cannot disregard this variable. To be precise, it is worth saying that in order to compare the costs among different technologies, namely conventional manufacturing processes and AM processes, it is necessary to evaluate all task need to achieve the same standard of the final product. Generally, cost models for AM need to include an account for [222]:

- Material waste and recycling cost

- Support structures

- Printing time

- Build volume occupation efficiency

- Product complexity and value

- Post-processing tasks and their duration

- Quality monitoring requirements

As shown earlier, most costs incurring in AM are time-driven. Therefore, when developing an activity-based costing model, all activities should be identified specifying their processing time. One proposed methodology includes the following three steps for isolating the main processes, as shown in Fig. 17 as well.

(1) Analyze all individual applicable activities

(2) Combine intercommunicating activities into logical sub-processes

(3) Summarize sub-processes into main process steps 

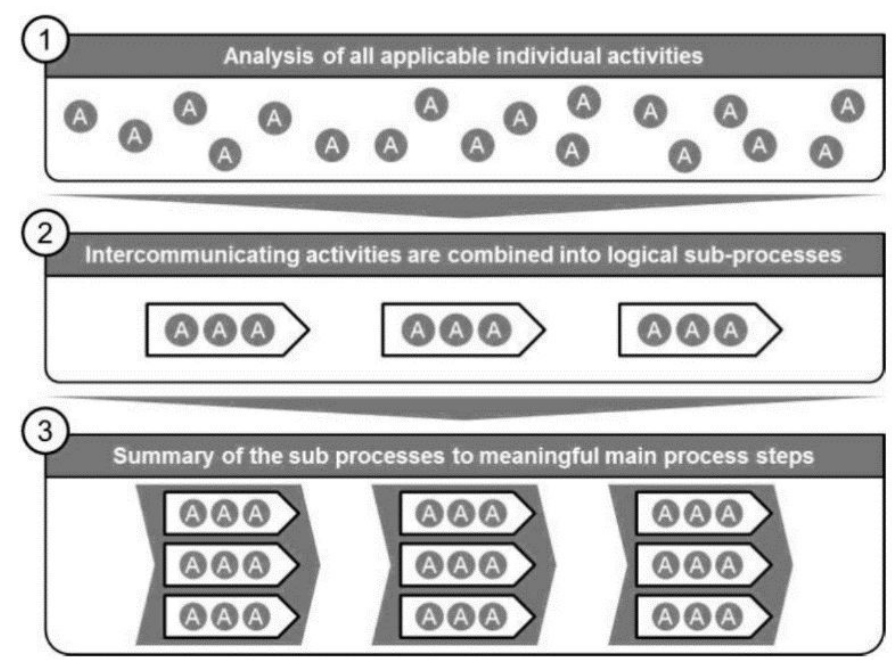

Figure 17. Identification of main process steps [222]

\subsubsection{The cost model for PBF processes}

For PBF systems, the above-mentioned analysis results in most cases in seven main process steps: “design \& planning, material processing, machine preparation, manufacturing, post-processing, administration, and sales \& quality" [222]. Then, parameterized cost functions are allocated to each activity so that total costs can be calculated [223]. This structured methodology also helps to identify what are the major contributors to cost. To this extent, Fig. 18 shows an example of cost sub-division for an SLM process. In the upper part, the cost contribution of each one of the seven main processes is detailed, whereas in the lower half the absolute value of those is shown.

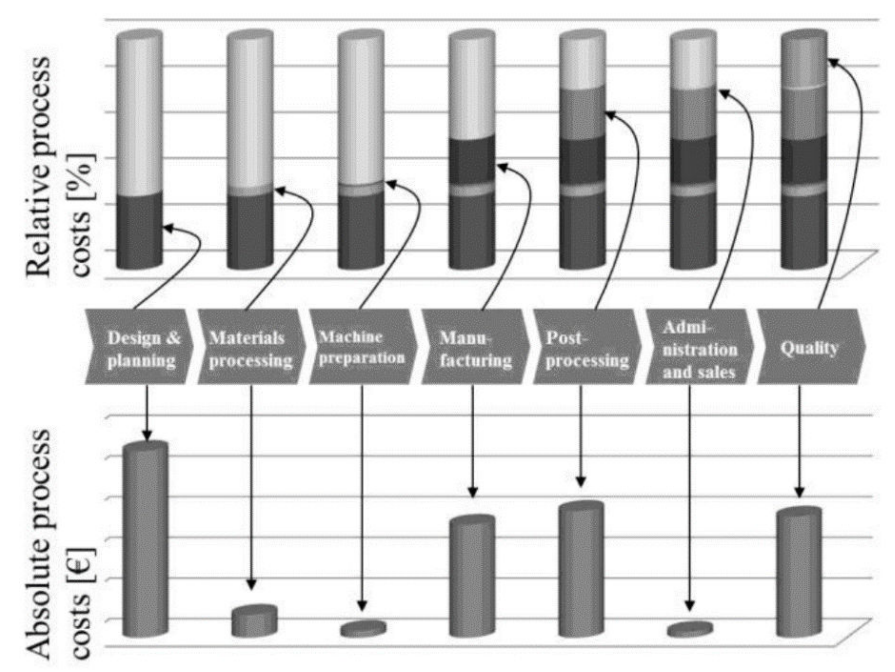

Figure 18. An example of cost sharing for the SLM process [224]

It can be noticed that for a typical PBF process the main cost voice is given by Design and Engineering work. Indeed, as discussed earlier, the parts and their position in the powder bed have to be studied carefully in order to achieve a good quality product. The second most costly step results to be the post-processing [225]. Again, this is due to the high-precision and intensive manual work to be done for structure removal, or for thermal stress relief [222]. 
Manufacturing takes obviously a big chunk of the total cost, and it includes the purchasing cost of the hardware, service, and maintenance, and in case of SLM, it also includes the wire erosion machine that is needed for separating the support structure from the build plate. Although the cost of an EBM machine is comparable to the purchasing cost of SLM one, the relative cost contribution might differ depending on the layer height utilized in the build, pre-heating and cooling [226, 227]. Regarding the material costs, there is a substantial difference in price between powder-based processes and wire-fed ones. For example, Ti64 powder comes in a price range of 300-500 $\$ / K g$ depending on the supplier, whereas the Ti64 wire, which is already commercially available for other uses, is one order of magnitude less expensive than that [5]. Finally, it can be said that all costs related to AM production can be allocated on an hourly base to the processes and that the resulting cost structure does not benefit from economies of scale. Nevertheless, it is worth noting that the high manual labor associated to the post-processing, support structures removal, the time spent for the engineering, and the job planning phases could strongly influence the hours of work associated for each part [183, 228].

In addition, as mentioned before, the build-volume occupation rate has a great impact on the final cost per part. It is clear that without filling the powder-bed completely the whole machine hourly rate has to be spread among the few parts produced creating the same effects seen on batch productions. Therefore, as it is visible from a sketch in Figure, the cost per part becomes lower and more constant when the full bed is filled [229].

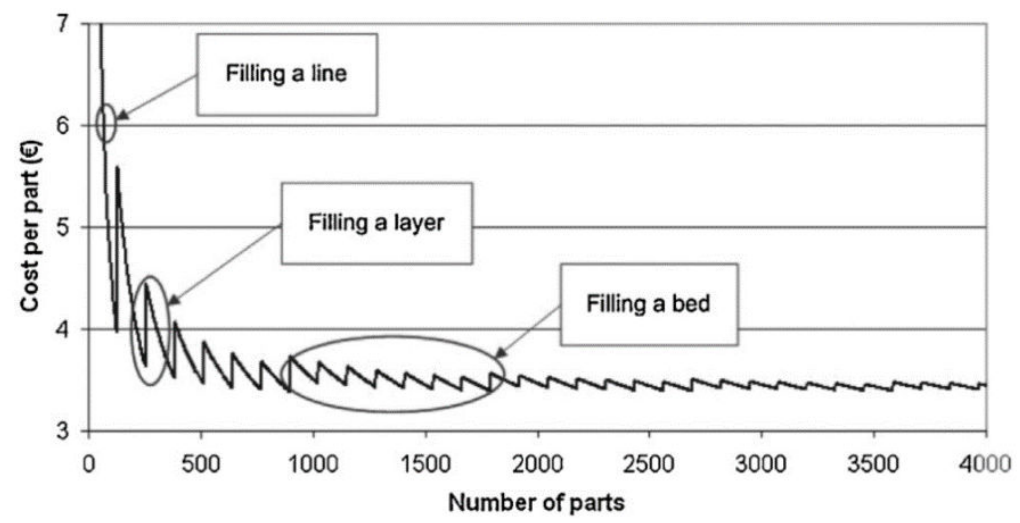

Figure 19. Scale economies scheme for PBF [229]

\subsubsection{Cost models for DED processes}

The DED processes such as the WAAM process are gaining increasing interest in the industry due to possible cost advantages and the ability to create large components [60]. Deposition rates can indeed go up to $4 \mathrm{Kg} / \mathrm{h}$ compared to $0.1 \mathrm{Kg} / \mathrm{h}$ achievable with PBF technologies. In fact, in order to achieve acceptable mechanical specifications, the deposition rate is kept at $1-2 \mathrm{Kg} / \mathrm{h}$ for the production of high-precision components.

Another difference is that there is no chamber, thus no pre-heating or vacuum processes are applicable. On the other hand, the residual stresses are reduced by cold rolling the just-deposited material thus adding up to the machine costs. In addition, because DED is "near net shape" processes, they need some machining after deposition is performed. This constraint clearly adds some difficulty to the process and increases the amount of postprocessing, thus the overall cost. As it is the case for powder-fed AM processes, a time-based Activity Based Costing $(A B C)$ model is the best-suited approach for evaluating the cost of DED processes [103].

In Figure, the specific cost for a part manufactured with the WAAM process is shown. For this example, the machine hardware cost was fixed at $£ 181,000$ of 2015 currency, and multiple curves are displayed according to the final part BTF ratio achieved. Particularly, it can be noticed that in general there is a specific cost reduction for high 
deposition rates and a meaningful difference can be seen above $0.5 \mathrm{Kg} / \mathrm{h}$. Also, as expected because of the material costs, lower BTF ratios considerably decrease the overall cost of manufacturing [79].

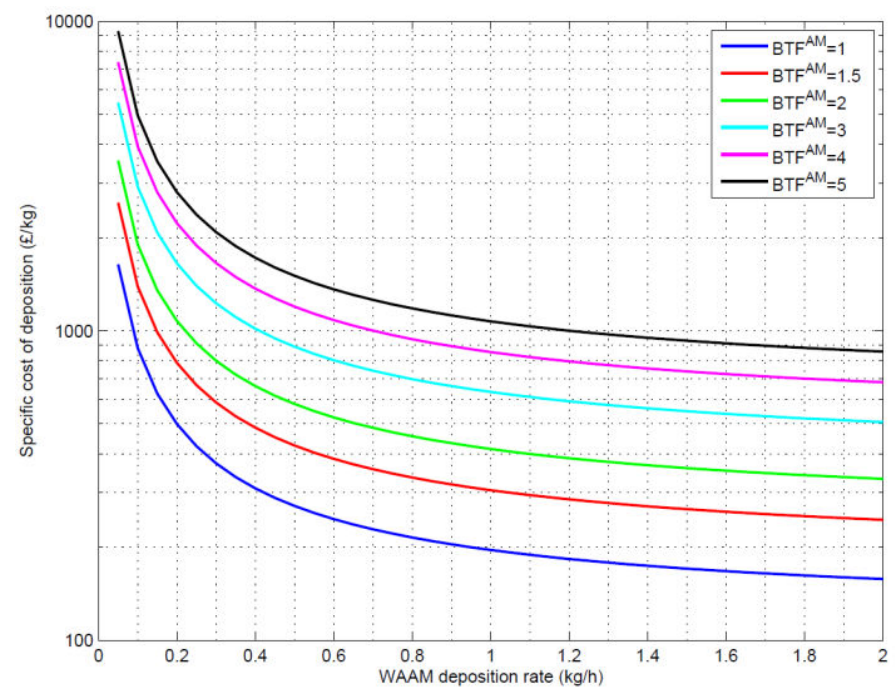

Figure 20. The specific cost of deposition for WAAM. The function of deposition rate and BTF ratio. Cost calculated with hardware cost of $f 181 \mathrm{~K}$ in 2015 currency [20]

The various activities involved in the process need to be identified, and a parametric cost associated with each of them. Figure 21 shows schematically the Figure 21 . The sequence of activities in the WAAM process. Then, in order to build a cost model for WAAM, the hourly rates of direct and indirect cost are used as an input while overheads such as administration and facility fees are excluded. The machine time would then be the other input necessary to calculate each activity cost.

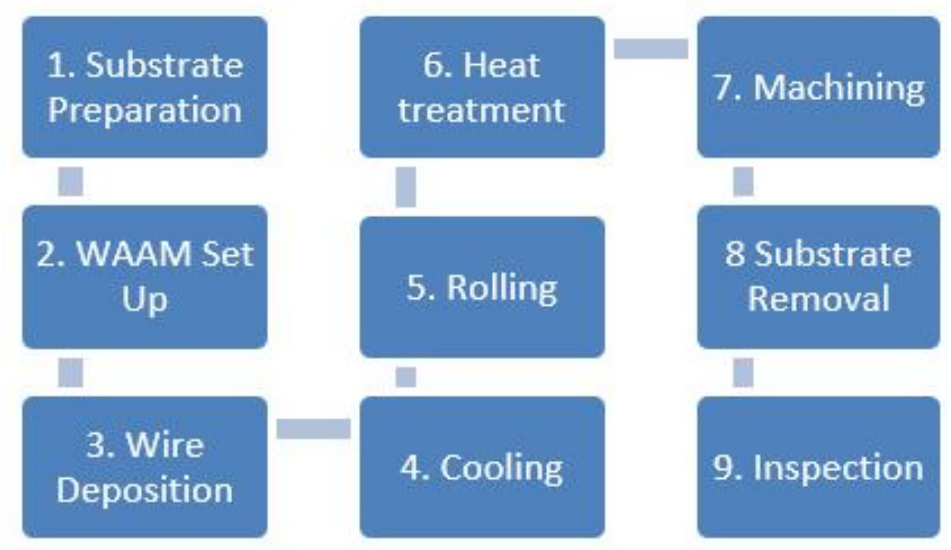

Figure 21. The sequence of activities in the WAAM process [103]

The total cost of the DED process is comparable with PBF technologies and conventional CNC. The investigation on DED process demonstrates how the inert gas flow can have a huge influence on the final cost because of the fact that there is no closed chamber and the parts are much larger than those produced by PBF. For the production of similar component geometry, WAAM results to be about on average $30 \%$ more economical than EBM and $70 \%$ compared to SLM, thanks to a lower machine cost which accounts for about $40 \%$ of the total. When compared to conventional CNC machining, the breakeven stands at a BTF ratio of 5, whereas for components with BTF ratios of 10 the cost reduction achievable by WAAM increases to 53\% [103]. Overall, Figure 22 represents a comparison 
between various AM equipment with consideration of four factors, namely, machinery, raw material,operational cost, and maintenance.

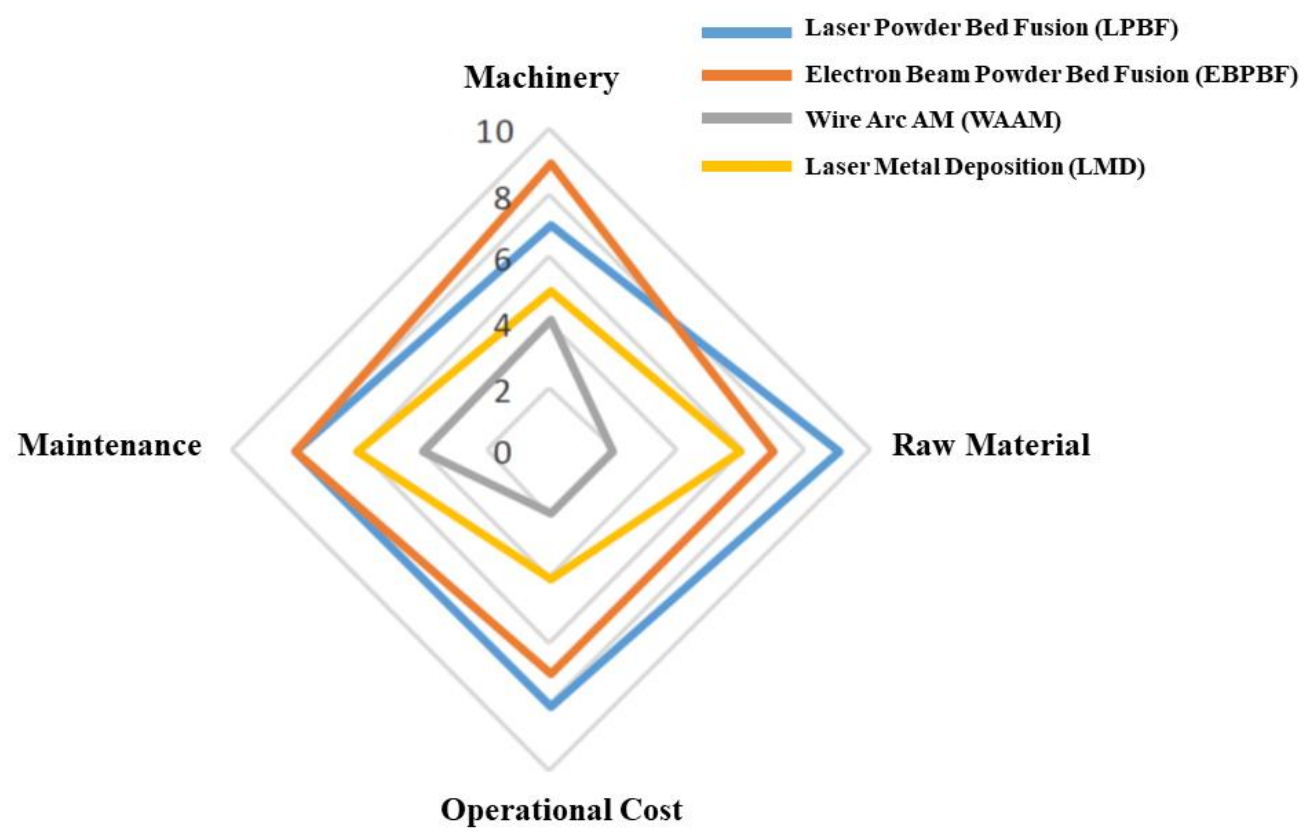

Figure 22. Cost Comparison between various AM equipment [109]

\subsection{SPARE PARTS \& SUPPLY CHAIN}

Some years ago, additive manufacturing processes were just used for prototyping and today there are more and more industries trying to exploit the benefits of AM in terms of design complexity and just-in-time production [39, 230, 231]. It is now worth discussing what the consequences are of the introduction of AM technologies in the supply chain, and particularly its impact on logistics and spare parts [172]. Indeed, if the end-user components are produced using AM, that would mean that their spare parts are produced with AM too. Alternatively, the original component could be produced by conventional techniques while the spare part could be produced by AM in order to achieve some benefits that will be listed below. According to the annual Global Report on AM released by Wohlers Associates, in 2012 only $28,1 \%$ of AM-fabricated parts were functional and this figure improved to $33,8 \%$ in 2016, showing that the demand for in-service support of AM parts will increase consequently [224].

\subsubsection{Digital spare parts}

Some benefits of AM technologies were already discussed in terms of production benefits, and these would have clear repercussions on the supply network. Reducing changeover times and the absence of specific tooling needed to provide a sort of agility and flexibility to the supplier, which can react more quickly to a request for part [224]. In aerospace, components have high capital asset value, because of the impact on the operations that just one missing spare part could have. Indeed, parts are changed according to scheduled maintenance that tries to reduce at minimum the unscheduled incidents, thus minimizing the aircraft grounding and maximizing revenue operations [224]. Nevertheless, unattended problems may arise, and airlines and their suppliers do not will to risk long times of unproductive downtimes that could cost from $\$ 10,000$ to more than $\$ 50,000$ per operational day lost to the airline, depending on the aircraft type. Thus, companies keep expensive inventories all the time to avoid risks of part unavailability. 
The AM processes seem to have good potential for achieving high spare part availability within a short lead-time and with low cost compared to conventional inventory stockpiling [232]. In addition, AM is well suited for covering the spares market of those products that are obsolete and have very low demand, such as parts for old types of aircraft whereby their downtime value is lower $[233,234]$.

Another possible outcome of AM in the spare parts supply chain would be the de-localization of production, bringing it closer to the final consumer and without the need for a centralized inventory [235-237]. This would allow a capillary network, also referred to as Digital Spare Parts (DSP), with lower inventory cost [238]. Nonetheless, stakeholders involved in the spare parts management system alerted about the risk of piracy. Data could be leaked during the transfer from the centralized data storage system and the production site. Another issue related with the implementation of the DSP network would be that today there is a lack of process standardization, and the production $A M$ sites receiving a given CAD data would need to make the difference according to the machine type and material. Some of the obstacles to the digitalization of the spare parts for the maintenance market have been identified by industry stakeholders and are shown in Table, where a possible cause of each obstacle and implication for the maintenance operations have been identified as well.

Table 4. Obstacles to digitalization of spare parts for maintenance [238]

\begin{tabular}{|c|c|c|}
\hline $\begin{array}{c}\text { The obstacle in digitization of spare } \\
\text { parts }\end{array}$ & Cause of obstacle & $\begin{array}{l}\text { The implication for maintenance } \\
\text { operations }\end{array}$ \\
\hline The high cost of AM & The high cost of AM machine hour price and materials & Increased price of producing components \\
\hline $\begin{array}{l}\text { The limited size of possible } \\
\text { components }\end{array}$ & Limited build envelopes of AM machinery & $\begin{array}{l}\text { Limited choice of components can be } \\
\text { produced with AM }\end{array}$ \\
\hline Inadequate quality of spare parts & AM accuracy limitations & \\
\hline $\begin{array}{l}\text { Variable quality between } A M \\
\text { machines }\end{array}$ & Lacking control of process parameters in AM & $\begin{array}{l}\text { Only parts that fit in the quality variability } \\
\text { can be produced with AM }\end{array}$ \\
\hline $\begin{array}{l}\text { Variable quality between shipments } \\
\text { of AM materials }\end{array}$ & $\begin{array}{l}\text { Lack of standardization of } \mathrm{AM} \text { material production } \\
\text { processes }\end{array}$ & \\
\hline Piracy & $\begin{array}{l}\text { Data leaks in the supply network and reverse } \\
\text { engineering of components }\end{array}$ & Loss of sales \\
\hline File version management & Poor ICT & Lack of conviction incorrect spare parts \\
\hline 3D model unavailability & $\begin{array}{l}\text { A component manufactured based on } 2 \mathrm{D} \text { drawings or } \\
\text { design subcontracted }\end{array}$ & $\begin{array}{l}\text { More work in } 3 \mathrm{D} \text { modeling and increased } \\
\text { labor cost }\end{array}$ \\
\hline $\begin{array}{l}\text { Difficulty in making } 3 \mathrm{D} \text { models from } \\
\text { obsolete components }\end{array}$ & The imprecision of 3D scanning & \\
\hline Parts are not ready after 3D printing & $\begin{array}{l}\text { Parts need to be post-processed and } 3 \mathrm{D} \text { scanning } \\
\text { does not provide this information }\end{array}$ & \\
\hline
\end{tabular}

It is worth noting that, although the first point identified in Table is the high cost of AM compared to conventional methods, it is widely recognized that in case of long tail products (not-frequent spares or obsolete parts) the would not represent a blocking issue. In fact, the over-cost of AM parts would be covered by the savings related to inventory costs, transportation costs from a centralized warehouse, and in terms of shorter lead-time [238]. The same stakeholders were asked in the interview what are the enablers of spare parts digitization, and some key interesting outcomes are listed below:

- High-complexity components would be perfectly suited to the DSP network due to the AM processes capability to produce complex parts at no extra cost. 
- Only small parts would be considered for DSP because of the actual AM processes constraints in terms of chamber size. The DED processes would not be considered in this case as they are better suited to the production of large structural parts rather than small components.

- Highly critical parts that necessitate the shortest possible lead-time for availability would be a good candidate of DSP. These would be components that could cause the grounding of the aircraft until a replacement part is provided.

- High-value parts instead are so relatively expansive that having them in stock generates important cash immobilization. Therefore, the DSP could reduce the overall value of these parts in stock, as the inventories would be kept in servers rather than on physical shelves.

\subsubsection{Spare parts consolidation}

Parts consolidation was earlier mentioned as an advantage of AM with respect to conventional manufacturing techniques, allowed by its unique capability of producing complex geometries with no extra cost or effort [175, 239]. The design benefits from this freedom by the means of optimized structures for their functionalities rather than for manufacturing constraints. This opportunity should be welcomed positively as most of the assembly failures in service generate from the parts couplings rather than from the part itself. This might have a drawback once the component enters into service though. Indeed, in case of failure, the whole part would need to be replaced as opposed to replacing the single broken component in case of assemblies of simpler parts [203, 205].

For critical aerospace parts, it is hard to think that no stock would be kept at all, leading to the conclusion that a very expensive inventory would end up on the shelf instead. In addition, the commonality effect on some parts that are used in multiple assemblies could be lost. Some key opportunities and drawbacks of design consolidation with regards to the supply chain and the spare parts are given in Table .

Table 5. Opportunities and drawbacks for supply chain with AM design consolidation [205]

\begin{tabular}{ll}
\hline \multicolumn{1}{c}{ Opportunities } & \multicolumn{1}{c}{ Drawbacks } \\
\hline + fewer assembly steps & - No replacement of sub-components \\
+ Shorter lead times & - Lost commonality effects \\
+ Simplified supply chain & - Potentially higher purchasing costs \\
+ Potentially higher reliability & - Potentially lower reliability \\
+ Performance improvements & - Stocking of more complex parts \\
+ Reduced tooling and setup effort & - Post-processing \\
+ Lower raw material usage & - Currently high supplier dependencies \\
+ Future low supplier dependencies & \\
\hline
\end{tabular}

Ashour Pour and Zanoni [240] have tried to model this problem by including as primary input factors the production cost, the reliability effects, and logistics costs. It is well agreed that integrating assembly parts into one single component can reduce the weight of the final part and optimize the design according to its functionality. Most of the predictive models of spare parts inventory management rely on two key variables: the number of working components into the assembly and their reliability, otherwise known as Mean Time Between Failures (MTBF) [241]. Removing many sub-assembly parts could not necessarily be the optimal solution. Apart from the integration feasibility through AM, the reliability of each part should be known before and after consolidation, as well as their production costs and inventory costs. Their investigation considered an assembly of three components, where they evaluated whether to integrate the design or not based on information such as reliability, inventory transportation costs and production costs. The assumption, in this case, was that the most valuable component was the least reliable too, and vice versa [240]. 
The ideal situation for parts consolidation comes to the case where production costs are relatively low, and their reliability is high. It is therefore interesting from a manufacturer's point of view to integrate the design and maximize the benefits. In the opposite side of the spectrum, when parts are relatively expensive to produce, and they are less reliable, it would be meaningful to have separate components and assembling them later. In intermediate cases of production cost and reliability, a partial consolidation could be envisaged, but finally, the decision might be influenced by other cost improvement decisions directed by the manufacturer [240].

Knofius et al. [205] compared AM-produced spare parts for an aircraft with the same part produced by conventional manufacturing and differentiated two cases for AM deployment. A central AM process with a capillary logistic network, which would be better suited for slow moving parts with strong demand variability, and a decentralized network of AM machines close to the final customers for fast moving spare parts [242, 243]. It was also modeled the economic feasibility of part consolidation through AM. The results often lead to the conclusion that conventional assemblies are more convenient than additively manufacture complex components, due to the fact that replacing the whole AM part is more expensive than just replacing a sub-component. This is true even when AM improves reliability and shortens replenishment lead times. Nevertheless, this comparison does not account for performance improvement of the new design, which was not possible with the conventionally manufactured assembly due to the known production constraints. In order to achieve cost reduction through parts, consolidation is to have a combination of higher overall reliability, lower total cost, and lower replenishment lead-time to minimize disruption [237, 244, 245].

It is also important to note that in the commercial aviation business, in order to minimize operational downtimes, airlines cover failures of expensive and critical parts with a "repair-by-replacement" policy. This policy means that even when a single part fails, the whole assembly or sub-assembly is replaced and sent to a specialized repair shop. There, the failed part is replaced or repaired if economical. In fact, for precaution, all aviation suppliers maintain a rotating stock of fully functional assemblies and sub-assemblies in various hubs around the world. These assemblies are ready to be installed and operate on aircraft as soon as it becomes necessary, sometimes within hours. This might seem a very expensive policy, but it would rather become reasonable when comparing the covered aircraft fleet value or the revenue loss due to operational downtime [246].

\subsection{ENVIRONMENTAL CONSEQUENCES}

In this section, final reasoning is done on the consequences of AM introduction into aerospace production systems and particularly regarding the later phase of the value chain. One of the reasons why aerospace is driving the research for achieving complex geometries and lighter aircraft components is that weight is a crucial factor for efficiency, fuel consumption, and performance in general. Very elementarily, an aircraft needs fuel for flying as many other transport means do, the difference relies on the fact that the aircraft weight has a direct and linear effect on its fuel consumption. Nowadays, there are about 20,000 large airplanes in the commercial aviation and cargo fleets worldwide, and Airbus and Boeing deliver about 1,600 more every year. This means that the global fleet will double in the next decade and the fuel consumption will increase accordingly. Therefore, the impact of reducing fuel combustion and greenhouse gas (GHG) emissions on aircraft produced today will generate effects over their whole life cycle [16]. It is estimated that every $100 \mathrm{Kg}$ of weight saved on an aircraft could save averagely $550 \mathrm{GJ}$ of fuel per year, corresponding to some 75 tons of vehicles weight reduction. Else, the airline could save about $300,000 \$$ per year in fuel efficiency, per each aircraft. To achieve this goal, AM could be helpful to reduce the overall mass.

Huang et al. [16] made an extensive study on the parts that could be replaced with AM-produced parts, on a shortmedium range aircraft. They estimated that between $9-17 \%$ of the total aircraft mass could be replaced by AM parts, and particularly 3-6\% attributable to Ti64 parts. As most of the aircraft body structure is now made of aluminum or carbon fiber, there is little opportunity for benefit. On the other hand, engines, pylons, and engines nacelles are bulky components with extensive use of Titanium, where it is estimated that about 1,000-2,000 Kg of components could be replaced using AM potentially resulting in a mass reduction of $380-820 \mathrm{Kg}$, or about $40 \%$ of the original components' weight [16]. As visible in Fig. 23, taking into account the North American fleet of just 
above 6,000 aircraft only, and assuming different incorporation rates of AM parts in cabin furnishing and equipment $(a, b, c)$ and engine parts $(d, e, f)$, the mass reduction effect can be estimated on the whole fleet over a 30 years period.
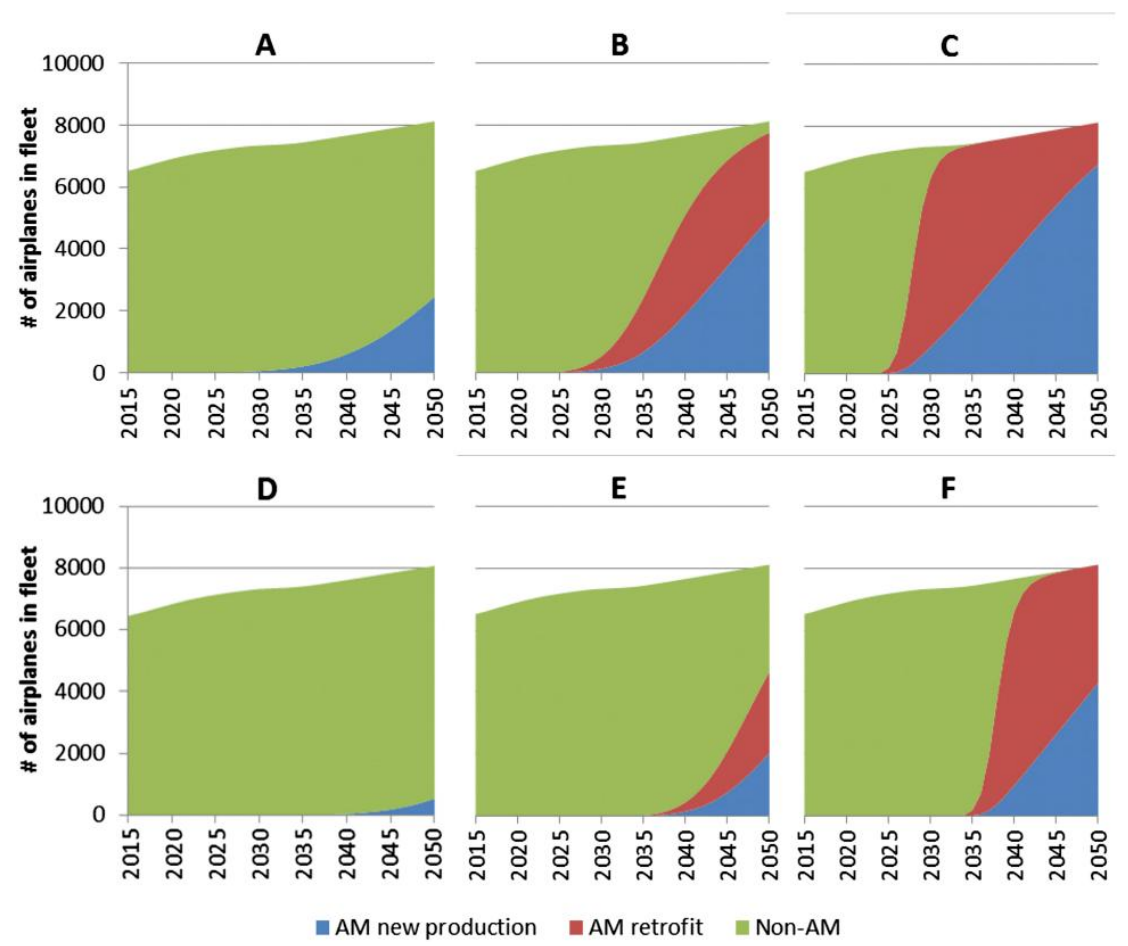

Figure 23. AM parts incorporation rate furnishings and equipment $(a, b, c)$ and engines $(d, e, f)[16]$.

From the curves, it is noticeable that in all integration scenarios AM-made furnishings are likely to appear first and more rapidly in commercial aircraft. Based on these curves and on the fuel saving figures mentioned earlier, it is possible to make fuel savings estimation for the whole fleet with different integration rates scenarios. In Fig. 24, it is visible that depending on the technology adoption rate there might be waves representing the fact that the production systems might struggle to keep up with the high demand.

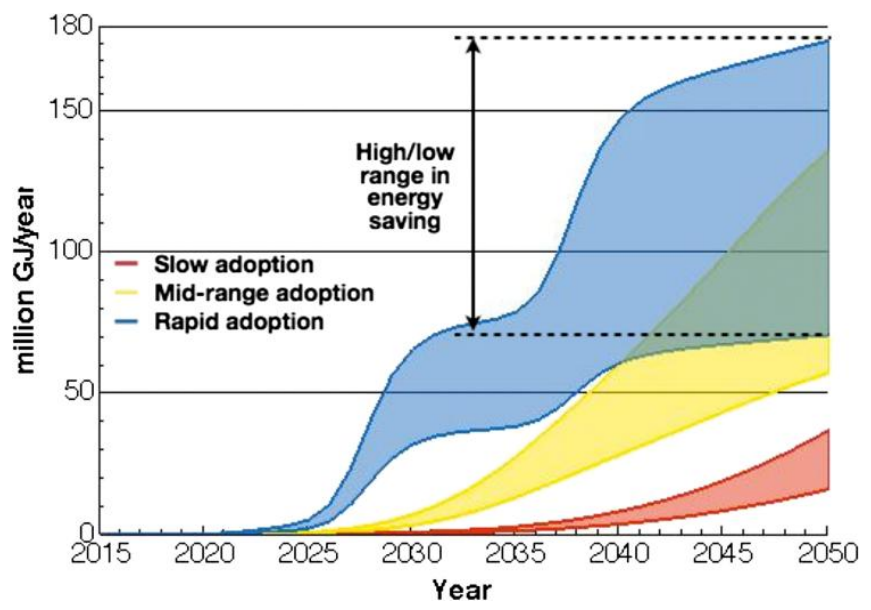

Figure 24. North American fleet primary energy use consequences of AM introduction [16] 
Moreover, it is estimated that only $2 \%$ to $3 \%$ of such energy efficiencies come from the manufacturing process, and the remaining is related to the aircraft service fuel savings due to the reduced weight [16, 110]. This evaluation only took into account the primary structure savings, but it must be said that weight reduction of primary components implies a reduction on secondary ones too because of the power load and stiffness required [247]. This is certainly an aspect that should be considered for redesigning components and achieve higher efficiency.

\section{CONCLUSIONS AND FUTURE TRENDS}

Nowadays the industrial landscape is highly competitive, and technologies can improve delivery times while reducing costs are being subjected to extensive research. This is particularly true in the aerospace sector, which is characterized by extremely complex and constrained supply chains, high-value products, and meticulous research for performing materials. It has been largely discussed and shown that one of the most promising manufacturing technologies is the AM process, and it is finally coming to prominence. By nature, it relies on the addition of one or more materials, in a layer-by-layer fashion; parts are "printed" directly from their CAD files, and with less material waste than that associated with conventional techniques.

Metal AM processes can be distinguished based on their heat source (laser beam, electron beam, or electric arc), type of feedstock (powder or wire), and whether the feedstock is pre-placed or fed at the point of deposition. Each combination of those coincides effectively with an AM process available commercially. Each process, due to the physics associated with a heat-source-feedstock combination, is better suited for certain applications than others are. Powder-bed AM processes, for instance, can produce highly optimized net-shape engineering structures, but their cost is high and the maximum size limited. On the other hand, wire-based processes are capable of producing large engineering structures in a cheap and timely manner, however, their resolution is relatively low, and they most likely require a finish-machining pass.

In order to be implemented extensively in a sector with such demanding regulations like the aerospace one, AM must be capable of proving process robustness, and repeatability of the mechanical properties that have been measured in the early trials. The properties of interest (tensile, fatigue, toughness, damage tolerance, etc.) have been met so far, albeit often after some sort of post-processing to recover defects such as porosity or lack-offusion. The question now is how to achieve the same results, consistently, in an industrial environment. Moreover, the same results must be achieved on geometries that can look rather different, potentially on different AM machines, and with feedstock coming from different suppliers. Other processing steps include a stress-relieving heat-treatment, which comes as no surprise given the existence of residual stress due to the cyclical heating/cooling nature of the additive processing; or mechanical cold-work, both in-process and post-process, to relieve residual stress as well as improving parts' microstructures and properties.

Other key steps towards industrial implementation are the addition of metrology capabilities to AM systems and the production of standards. The former will eventually lead to closed-loop control systems, capable of making adjustments to process parameters, on the fly, to meet the aforementioned requirements of integrity. The latter will eventually lead to widely accepted procedures that will ensure comparable results, regardless of who has built the part, and where it has been produced.

In order to better evaluate the introduction of AM technologies into a manufacturing system, the opportunities deriving from them should be analyzed carefully. It has been mentioned and discussed that AM allows producing more complex geometries, thus changing the design philosophy towards better optimization, better performances, with special features creating new utilization possibilities. Nonetheless, the impact on supply chain costs and spare parts market could be negative in case of high parts integration, a topic that would need further research.

Concerning production costs, it can be concluded that DED processes show combined advantages of rapid deposition and machining. For parts with high BTF ratios, these processes are extremely valuable for large components with simple geometries where material cost is a key indicator. On the other hand, PBF processes are extremely interesting for aviation for their capability of making difficult and optimized designs, saving weight on both primary and secondary elements. This was demonstrated to have a greater effect on the service life of 
aircraft, generating fuel economies as well as lower gas emissions for the benefit of the collectivity. It seems that the opportunities deriving from AM go far beyond the pure manufacturing efficiency, and they could affect positively the entire product life-cycle, the supply chains and the environment for the long-term.

Overall, AM technology is still not mature and needs more development to reduce the material and machine costs, generate faster and more accurate printing methods and work autonomously. The future of AM in the aerospace industry considerably depends on innovation in AM technologies and methods, advances in materials, and even equipping the existing manufacturing systems. In particular, it will be beyond the production of only monolithic products. In fact, the technology will be developed and provide more opportunities for users by the application of advanced materials, smart structures, and functionally graded materials (FGM). However, there would be many new challenges in the area of production quality, structural design, and manufacturing systems.

\section{References}

1. Frazier, W.E., Metal additive manufacturing: a review. Journal of Materials Engineering and Performance, 2014. 23(6): p. 1917-1928.

2. Huang, S.H., et al., Additive manufacturing and its societal impact: a literature review. The International Journal of Advanced Manufacturing Technology, 2013. 67(5-8): p. 1191-1203.

3. Guo, N. and M.C. Leu, Additive manufacturing: technology, applications and research needs. Frontiers of Mechanical Engineering, 2013. 8(3): p. 215-243.

4. Rejeski, D., F. Zhao, and Y. Huang, Research needs and recommendations on environmental implications of additive manufacturing. Additive Manufacturing, 2018. 19: p. 21-28.

5. Thompson, M.K., et al., Design for Additive Manufacturing: Trends, opportunities, considerations, and constraints. CIRP annals, 2016. 65(2): p. 737-760.

6. Khajavi, S.H., J. Partanen, and J. Holmström, Additive manufacturing in the spare parts supply chain. Computers in industry, 2014. 65(1): p. 50-63.

7. Wohlers, T., Additive Manufacturing and 3D Printing, State of the Industry, Annu. Worldw. Prog. Rep. Wohlers Assoc. USA, 2012.

8. Kruth, J.-P., M.-C. Leu, and T. Nakagawa, Progress in additive manufacturing and rapid prototyping. Cirp Annals, 1998. 47(2): p. 525-540.

9. Dehoff, R.R., et al., Case study: additive manufacturing of aerospace brackets. Advanced Materials and Processes, 2013. 171(3).

10. Liu, R., et al., Aerospace applications of laser additive manufacturing, in Laser Additive Manufacturing. 2017, Elsevier. p. 351-371.

11. Uriondo, A., M. Esperon-Miguez, and S. Perinpanayagam, The present and future of additive manufacturing in the aerospace sector: A review of important aspects. Proceedings of the Institution of Mechanical Engineers, Part G: Journal of Aerospace Engineering, 2015. 229(11): p. 2132-2147.

12. Schiller, G. Additive manufacturing for aerospace. in Aerospace Conference, 2015 IEEE. 2015. IEEE.

13. Timmis, A.J., et al., Environmental impact assessment of aviation emission reduction through the implementation of composite materials. The International Journal of Life Cycle Assessment, 2015. 20(2): p. 233-243.

14. Barnes, J.E., W. Peter, and C.A. Blue. Evaluation of low cost titanium alloy products. in Materials Science Forum. 2009. Trans Tech Publ.

15. Qiu, X., Effect of rolling on fatigue crack growth rate of Wire and Arc Additive Manufacture (WAAM) processed Titanium. 2013.

16. Huang, R., et al., Energy and emissions saving potential of additive manufacturing: the case of lightweight aircraft components. Journal of Cleaner Production, 2016. 135: p. 1559-1570.

17. Nickels, L., AM and aerospace: an ideal combination. Metal Powder Report, 2015. 70(6): p. 300-303.

18. Ralph, B., Method of making decorative articles. 1925, Google Patents.

19. Parraman, C. and M.V.O. Segovia, 2.5 D Printing: Bridging the Gap Between 2D and 3D Applications. 2018: John Wiley \& Sons. 
20. Martina, F., et al., Microstructure of interpass rolled wire+ arc additive manufacturing Ti-6Al-4V components. Metallurgical and Materials Transactions A, 2015. 46(12): p. 6103-6118.

21. Technologies, A.C.F.o.A.M. and A.C.F.o.A.M.T.S.F.o. Terminology, Standard terminology for additive manufacturing technologies. 2012: ASTM International.

22. Campbell, I., D. Bourell, and I. Gibson, Additive manufacturing: rapid prototyping comes of age. Rapid prototyping journal, 2012. 18(4): p. 255-258.

23. Chua, C.K. and K.F. Leong, 3D Printing and Additive Manufacturing: Principles and Applications (with Companion Media Pack) of Rapid Prototyping Fourth Edition. 2014: World Scientific Publishing Company.

24. Bassoli, E., et al., 3D printing technique applied to rapid casting. Rapid Prototyping Journal, 2007. 13(3): p. 148-155.

25. Hiemenz, J., 3D printing jigs, fixtures and other manufacturing tools. Stratasys, Inc, 2011.

26. Bhavar, V., et al. A review on powder bed fusion technology of metal additive manufacturing. in 4th International Conference and Exhibition on Additive Manufacturing Technologies-AM-2014, September. 2014.

27. Das, S., R. Bansal, and J. Gambone, Systems and methods for additive manufacturing and repair of metal components. 2016, Google Patents.

28. Wits, W.W., J.R.R. García, and J.M.J. Becker, How additive manufacturing enables more sustainable enduser maintenance, repair and overhaul (MRO) strategies. Procedia CIRP, 2016. 40: p. 693-698.

29. King, W.E., et al., Laser powder bed fusion additive manufacturing of metals; physics, computational, and materials challenges. Applied Physics Reviews, 2015. 2(4): p. 041304.

30. Sing, S.L., et al., Laser and electron-beam powder-bed additive manufacturing of metallic implants: A review on processes, materials and designs. Journal of Orthopaedic Research, 2016. 34(3): p. 369-385.

31. Mueller, B., Additive manufacturing technologies-Rapid prototyping to direct digital manufacturing. Assembly Automation, 2012. 32(2).

32. Gu, D., et al., Densification behavior, microstructure evolution, and wear performance of selective laser melting processed commercially pure titanium. Acta Materialia, 2012. 60(9): p. 3849-3860.

33. Attar, H., et al., Manufacture by selective laser melting and mechanical behavior of commercially pure titanium. Materials Science and Engineering: A, 2014. 593: p. 170-177.

34. Uhlmann, E., et al., Additive manufacturing of titanium alloy for aircraft components. Procedia CIRP, 2015. 35: p. 55-60.

35. Wang, X., et al., The effect of atmosphere on the structure and properties of a selective laser melted Al12Si alloy. Materials Science and Engineering: A, 2014. 597: p. 370-375.

36. Elahinia, M., et al., Fabrication of NiTi through additive manufacturing: a review. Progress in Materials Science, 2016. 83: p. 630-663.

37. Di, W., et al., Study on energy input and its influences on single-track, multi-track, and multi-layer in SLM. The International Journal of Advanced Manufacturing Technology, 2012. 58(9-12): p. 1189-1199.

38. Brandt, M., et al. High-value SLM aerospace components: from design to manufacture. in Advanced Materials Research. 2013. Trans Tech Publ.

39. Strano, G., et al., A new approach to the design and optimisation of support structures in additive manufacturing. The International Journal of Advanced Manufacturing Technology, 2013. 66(9-12): p. 1247-1254.

40. Hussein, A., et al., Advanced lattice support structures for metal additive manufacturing. Journal of Materials Processing Technology, 2013. 213(7): p. 1019-1026.

41. Agius, D., et al., Cyclic plasticity and microstructure of as-built SLM Ti-6Al-4V: The effect of build orientation. Materials Science and Engineering: A, 2017. 701: p. 85-100.

42. Leutenecker-Twelsiek, B., C. Klahn, and M. Meboldt, Considering part orientation in design for additive manufacturing. Procedia CIRP, 2016. 50: p. 408-413.

43. Zhang, H., et al., The effects of ultrasonic nanocrystal surface modification on the fatigue performance of 3D-printed Ti64. International Journal of Fatigue, 2017. 103: p. 136-146.

44. Shiomi, M., et al., Residual stress within metallic model made by selective laser melting process. CIRP Annals-Manufacturing Technology, 2004. 53(1): p. 195-198.

45. Liu, Y., Y. Yang, and D. Wang, A study on the residual stress during selective laser melting (SLM) of metallic powder. The International Journal of Advanced Manufacturing Technology, 2016. 87(1-4): p. 647-656. 
46. Yadroitsava, I., et al. Residual stress in SLM Ti6Al4V alloy specimens. in Materials Science Forum. 2015. Trans Tech Publ.

47. Song, B., et al., Vacuum heat treatment of iron parts produced by selective laser melting: microstructure, residual stress and tensile behavior. Materials \& Design (1980-2015), 2014. 54: p. 727-733.

48. Aboulkhair, N.T., et al., Improving the fatigue behaviour of a selectively laser melted aluminium alloy: Influence of heat treatment and surface quality. Materials \& Design, 2016. 104: p. 174-182.

49. Murr, L.E., et al., Metal fabrication by additive manufacturing using laser and electron beam melting technologies. Journal of Materials Science \& Technology, 2012. 28(1): p. 1-14.

50. Petrovic, V., et al., Additive layered manufacturing: sectors of industrial application shown through case studies. International Journal of Production Research, 2011. 49(4): p. 1061-1079.

51. Rafi, H., et al., Microstructures and mechanical properties of Ti6Al4V parts fabricated by selective laser melting and electron beam melting. Journal of materials engineering and performance, 2013. 22(12): p. 3872-3883.

52. Gong, X., T. Anderson, and K. Chou. Review on powder-based electron beam additive manufacturing technology. in ASME/ISCIE 2012 international symposium on flexible automation. 2012. American Society of Mechanical Engineers.

53. Galati, M. and L. Iuliano, A literature review of powder-based electron beam melting focusing on numerical simulations. Additive Manufacturing, 2018. 19: p. 1-20.

54. Baumers, M., et al., Energy inputs to additive manufacturing: does capacity utilization matter. Eos, 2011. 1000(270): p. 30-40.

55. Li, X., et al., Fabrication and characterization of porous Ti6Al4V parts for biomedical applications using electron beam melting process. Materials Letters, 2009. 63(3-4): p. 403-405.

56. Zhao, X., et al., Comparison of the microstructures and mechanical properties of Ti-6Al-4V fabricated by selective laser melting and electron beam melting. Materials \& Design, 2016. 95: p. 21-31.

57. Koike, M., et al., Evaluation of titanium alloys fabricated using rapid prototyping technologies - electron beam melting and laser beam melting. Materials, 2011. 4(10): p. 1776-1792.

58. Song, B., et al., Effects of processing parameters on microstructure and mechanical property of selective laser melted Ti6Al4V. Materials \& Design, 2012. 35: p. 120-125.

59. Paskual, A., P. Álvarez, and A. Suárez, Study on arc welding processes for high deposition rate additive manufacturing. Procedia Cirp, 2018. 68: p. 358-362.

60. Busachi, A., et al., A review of additive manufacturing technology and cost estimation techniques for the defence sector. CIRP Journal of Manufacturing Science and Technology, 2017. 19: p. 117-128.

61. Loeber, L., et al. Comparison of selective laser and electron beam melted titanium aluminides. in Proceedings of the Solid Freeform Fabrication Symposium, Austin, TX, USA. 2011.

62. Casavola, C., S. Campanelli, and C. Pappalettere. Experimental analysis of residual stresses in the selective laser melting process. in Proccedings of the XIth International Congress and Exposition, Orlando, Florida, USA. 2008.

63. Edwards, P. and M. Ramulu, Fatigue performance evaluation of selective laser melted Ti-6Al-4V. Materials Science and Engineering: A, 2014. 598: p. 327-337.

64. Leuders, S., et al., On the mechanical behaviour of titanium alloy TiAl6V4 manufactured by selective laser melting: Fatigue resistance and crack growth performance. International Journal of Fatigue, 2013. 48: p. 300-307.

65. Murr, L.E. and W.L. Johnson, 3D metal droplet printing development and advanced materials additive manufacturing. Journal of Materials Research and Technology, 2017. 6(1): p. 77-89.

66. Gibson, I., D. Rosen, and B. Stucker, Directed energy deposition processes, in Additive Manufacturing Technologies. 2015, Springer. p. 245-268.

67. Wolff, S.J., et al., A framework to link localized cooling and properties of directed energy deposition (DED)-processed Ti-6Al-4V. Acta Materialia, 2017. 132: p. 106-117.

68. Fujishima, M., et al., Study on factors for pores and cladding shape in the deposition processes of Inconel 625 by the directed energy deposition (DED) method. CIRP Journal of Manufacturing Science and Technology, 2017. 19: p. 200-204.

69. Cortina, M., et al., Latest Developments in Industrial Hybrid Machine Tools that Combine Additive and Subtractive Operations. Materials, 2018. 11(12): p. 2583. 
70. Wirth, F., S. Arpagaus, and K. Wegener, Analysis of melt pool dynamics in laser cladding and direct metal deposition by automated high-speed camera image evaluation. Additive Manufacturing, 2018. 21: p. 369382.

71. Brandl, E., et al., Additive manufactured Ti-6Al-4V using welding wire: comparison of laser and arc beam deposition and evaluation with respect to aerospace material specifications. Phys. Procedia, 2010. 5(Pt 2): p. 595-606.

72. Allen, J., An investigation into the comparative costs of additive manufacture vs. machine from solid for aero engine parts. 2006, ROLLS-ROYCE PLC DERBY (UNITED KINGDOM).

73. Taminger, K. and R.A. Hafley, Electron beam freeform fabrication: a rapid metal deposition process. 2003.

74. Stecker, S., et al. Advanced electron beam free form fabrication methods \& technology. in American Welding Society Conference, Missoula, MT, Nov. 2006.

75. Tayon, W.A., et al., Correlation between microstructure and mechanical properties in an Inconel 718 deposit produced via electron beam freeform fabrication. Journal of Manufacturing Science and Engineering, 2014. 136(6): p. 061005.

76. Hafley, R., K. Taminger, and R. Bird. Electron Beam Freeform Fabrication in the Space Environment. in 45th AIAA Aerospace Sciences Meeting and Exhibit. 2007.

77. Heck, D., et al. Electron Beam Deposition of Ti 6-4 for Aerospace Structures. in AIAA SPACE 2007 Conference \& Exposition. 2007.

78. Yu, P., et al. Electron beam processing of aluminium alloys. in Materials science forum. 2009. Trans Tech Publ.

79. Martina, F. and S. Williams, Wire+ arc additive manufacturing vs. traditional machining from solid: a cost comparison. JOURNAL OF ENGINEERING DESIGN, 2015. 595.

80. Ding, J., et al., Thermo-mechanical analysis of wire and arc additive layer manufacturing process on large multi-layer parts. Computational Materials Science, 2011. 50(12): p. 3315-3322.

81. Ding, D., et al., A multi-bead overlapping model for robotic wire and arc additive manufacturing (WAAM). Robotics and Computer-Integrated Manufacturing, 2015. 31: p. 101-110.

82. Assunção, E., et al., LASIMM-AM production of large scale engineering structures.

83. Martina, F., et al., Tandem metal inert gas process for high productivity wire arc additive manufacturing in stainless steel. Additive Manufacturing, 2019. 25: p. 545-550.

84. Qiu, C., et al., Fabrication of large Ti-6Al-4V structures by direct laser deposition. Journal of Alloys and Compounds, 2015. 629: p. 351-361.

85. Szost, B.A., et al., A comparative study of additive manufacturing techniques: Residual stress and microstructural analysis of CLAD and WAAM printed Ti-6Al-4V components. Materials \& Design, 2016. 89: p. 559-567.

86. Selcuk, C., Laser metal deposition for powder metallurgy parts. Powder Metallurgy, 2011. 54(2): p. 94-99.

87. Mahamood, R.M., et al., Laser metal deposition of Ti6Al4V: a study on the effect of laser power on microstructure and microhardness. 2013.

88. Baufeld, B., E. Brandl, and O. Van der Biest, Wire based additive layer manufacturing: Comparison of microstructure and mechanical properties of Ti-6Al-4V components fabricated by laser-beam deposition and shaped metal deposition. Journal of Materials Processing Technology, 2011. 211(6): p. 1146-1158.

89. Akman, E., et al., Laser welding of Ti6Al4V titanium alloys. Journal of materials processing technology, 2009. 209(8): p. 3705-3713.

90. Mehrpouya, M., A. Gisario, and M. Elahinia, Laser welding of NiTi shape memory alloy: A review. Journal of Manufacturing Processes, 2018. 2018(31): p. 162-186.

91. Vilar, R. and A. Almeida, Laser surface treatment of biomedical alloys, in Laser Surface Modification of Biomaterials. 2016, Elsevier. p. 35-75.

92. Schubert, E., et al., Light-weight structures produced by laser beam joining for future applications in automobile and aerospace industry. Journal of Materials Processing Technology, 2001. 115(1): p. 2-8.

93. Gisario, A., M. Mehrpouya, and E. Pizzi, Dissimilar joining of transparent Poly (ethylene terephthalate) to aluminum 7075 sheets using a diode laser. Journal of Laser Applications, 2017. 29(2): p. 022418.

94. Gisario, A., et al., LaserOrigami (LO) of three-dimensional (3D) components: Experimental analysis and numerical modelling. Journal of Manufacturing Processes, 2016. 23: p. 242-248. 
95. Sibillano, T., et al., A study of the shielding gas influence on the laser beam welding of AA5083 aluminium alloys by in-process spectroscopic investigation. Optics and Lasers in Engineering, 2006. 44(10): p. 10391051.

96. Gisario, A., et al., Laser-assisted bending of Titanium Grade-2 sheets: Experimental analysis and numerical simulation. Optics and Lasers in Engineering, 2017. 92: p. 110-119.

97. Wang, H., et al., Effect of assist gas flow on the gas shielding during laser deep penetration welding. Journal of Materials Processing Technology, 2007. 184(1-3): p. 379-385.

98. Mehrpouya, M., et al., Laser welding of NiTi shape memory sheets using a diode laser. Optics and Laser Technology, 2018. 108C p. 142-149.

99. Ming, G., Z. Xiaoyan, and H. Qianwu, Effects of gas shielding parameters on weld penetration of CO2 laserTIG hybrid welding. Journal of Materials Processing Technology, 2007. 184(1-3): p. 177-183.

100. Chae, H., et al., The effect of shielding gas composition in CO2 laser-gas metal arc hybrid welding. Proceedings of the Institution of Mechanical Engineers, Part B: Journal of Engineering Manufacture, 2008. 222(11): p. 1315-1324.

101. Nowotny, S., et al., Laser beam build-up welding: precision in repair, surface cladding, and direct 3D metal deposition. Journal of Thermal Spray Technology, 2007. 16(3): p. 344-348.

102. Yu, J., et al., Material Properties of Ti6Al4 V Parts Produced by Laser Metal Deposition. Physics Procedia, 2012. 39: p. 416-424.

103. Cunningham, C., et al., Cost modelling and sensitivity analysis of wire and arc additive manufacturing. Procedia Manufacturing, 2017. 11: p. 650-657.

104. Brandl, E., A. Schoberth, and C. Leyens, Morphology, microstructure, and hardness of titanium (Ti-6Al-4V) blocks deposited by wire-feed additive layer manufacturing (ALM). Materials Science and Engineering: $A$, 2012. 532: p. 295-307.

105. Gockel, J., J. Beuth, and K. Taminger, Integrated control of solidification microstructure and melt pool dimensions in electron beam wire feed additive manufacturing of Ti-6Al-4V. Additive Manufacturing, 2014. 1: p. 119-126.

106. Kelbassa, I., et al. Manufacture and repair of aero engine components using laser technology. in Pacific International Conference on Applications of Lasers and Optics. 2008. LIA.

107. Dey, N.K., Additive manufacturing laser deposition of Ti-6Al-4V for aerospace repair application. 2014.

108. Petrat, T., et al., Laser metal deposition as repair technology for a gas turbine burner made of Inconel 718. Physics Procedia, 2016. 83: p. 761-768.

109. Alberto Garcia-Colomo, D.W., Filomeno Martina and Stewart W. Williams, A comparison framework to support the selection of the best additive manufacturing process for specific aerospace applications. International Journal of Rapid Manufacturing, 2019.

110. Liu, S. and Y.C. Shin, Additive manufacturing of Ti6Al4V alloy: A review. Materials \& Design, 2019. 164: p. 107552.

111. Antonysamy, A.A., Microstructure, texture and mechanical property evolution during additive manufacturing of Ti6Al4V alloy for aerospace applications. 2012, The University of Manchester (United Kingdom).

112. Maric, J., F. Rodhain, and Y. Barlette, Frugal innovations and 3D printing: insights from the field. Journal of Innovation Economics \& Management, 2016(3): p. 57-76.

113. Bora, R. TITANIUM SPONGE FOR AEROSPACE \& DEFENSE MARKET BY PRODUCT TYPES, WITH SALES VOLUME, REVENUE, MARKET SHARE, PRICE, GROWTH RATE BY 2024. 2018; Available from: http://www.thecampingcanuck.com/titanium-sponge-aerospace-defense-market-product-types-salesvolume-revenue-market-share-price-growth-rate-2024/22373/.

114. Williams, G., R. Trask, and I. Bond, A self-healing carbon fibre reinforced polymer for aerospace applications. Composites Part A: Applied Science and Manufacturing, 2007. 38(6): p. 1525-1532.

115. Soutis, C., Carbon fiber reinforced plastics in aircraft construction. Materials Science and Engineering: A, 2005. 412(1-2): p. 171-176.

116. Marsh, G., Airbus takes on Boeing with reinforced plastic A350 XWB. Reinforced plastics, 2007. 51(11): p. 26-29.

117. Airbus. A350 XWB Family, Shaping the future of air travel. 2018; Available from: https://www.airbus.com/aircraft/passenger-aircraft/a350xwb-family.html. 
118. Marsh, G., Aero engines lose weight thanks to composites. Reinforced Plastics, 2012. 56(6): p. 32-35.

119. Tomblin, J., Overview of Composite Material Trends in Aviation Manufacturing. National Institute for Aviation Research (NIAR), 2006.

120. Mukherjee, T., W. Zhang, and T. DebRoy, An improved prediction of residual stresses and distortion in additive manufacturing. Computational Materials Science, 2017. 126: p. 360-372.

121. Megahed, M., et al., Metal additive-manufacturing process and residual stress modeling. Integrating Materials and Manufacturing Innovation, 2016. 5(1): p. 4.

122. Zhang, J., et al., Fatigue crack propagation behaviour in wire+ arc additive manufactured Ti-6Al-4V: Effects of microstructure and residual stress. Materials \& Design, 2016. 90: p. 551-561.

123. Vrancken, B., Study of residual stresses in selective laser melting. 2016.

124. Shipley, H., et al., Optimisation of process parameters to address fundamental challenges during selective laser melting of Ti-6Al-4V: A review. International Journal of Machine Tools and Manufacture, 2018. 128: p. 1-20.

125. Parry, L.A., Investigation of residual stress in selective laser melting. 2018, University of Nottingham.

126. Hackel, L., et al., Laser peening: A tool for additive manufacturing post-processing. Additive Manufacturing, 2018. 24: p. 67-75.

127. Kalentics, N., et al., Tailoring residual stress profile of selective laser melted parts by laser shock peening. Additive Manufacturing, 2017. 16: p. 90-97.

128. Pyka, G., et al., Surface roughness and morphology customization of additive manufactured open porous Ti6Al4V structures. Materials, 2013. 6(10): p. 4737-4757.

129. Turner, B.N. and S.A. Gold, A review of melt extrusion additive manufacturing processes: II. Materials, dimensional accuracy, and surface roughness. Rapid Prototyping Journal, 2015. 21(3): p. 250-261.

130. Stavroulakis, P. and R.K. Leach, Invited review article: review of post-process optical form metrology for industrial-grade metal additive manufactured parts. Review of Scientific instruments, 2016. 87(4): p. 041101.

131. Vrancken, B., et al., Heat treatment of Ti6Al4V produced by Selective Laser Melting: Microstructure and mechanical properties. Journal of Alloys and Compounds, 2012. 541: p. 177-185.

132. Prashanth, K., et al., Microstructure and mechanical properties of Al-12Si produced by selective laser melting: Effect of heat treatment. Materials Science and Engineering: A, 2014. 590: p. 153-160.

133. Chandramohan, P., et al., Laser Additive Manufactured Ti-6Al-4V Alloy: Heat Treatment Studies. Transactions of the Indian Institute of Metals, 2018. 71(3): p. 579-587.

134. Herzog, D., et al., Additive manufacturing of metals. Acta Materialia, 2016. 117: p. 371-392.

135. Scharowsky, T., et al., Influence of the scanning strategy on the microstructure and mechanical properties in selective electron beam melting of Ti-6Al-4V. Advanced Engineering Materials, 2015. 17(11): p. 15731578.

136. Černašejus, O., et al., Surface Laser Processing of Additive Manufactured 1.2709 Steel Parts: Preliminary Study. Advances in Materials Science and Engineering, 2019. 2019.

137. dos Santos Solheid, J., H.J. Seifert, and W. Pfleging, Laser surface modification and polishing of additive manufactured metallic parts. Procedia CIRP, 2018. 74: p. 280-284.

138. Bhaduri, D., et al., Laser polishing of 3D printed mesoscale components. Applied Surface Science, 2017. 405: p. 29-46.

139. Hassanin, H., et al., Surface finish improvement of additive manufactured metal parts, in Micro and Precision Manufacturing. 2018, Springer. p. 145-164.

140. Cai, C., et al., Effect of hot isostatic pressing procedure on performance of Ti6Al4V: surface qualities, microstructure and mechanical properties. Journal of Alloys and Compounds, 2016. 686: p. 55-63.

141. Tammas-Williams, S., et al., The effectiveness of hot isostatic pressing for closing porosity in titanium parts manufactured by selective electron beam melting. Metallurgical and Materials Transactions A, 2016. 47(5): p. 1939-1946.

142. Lewandowski, J.J. and M. Seifi, Metal additive manufacturing: a review of mechanical properties. Annual Review of Materials Research, 2016. 46: p. 151-186.

143. EMPA, Introduction to Additive Manufacturing Technology, E.P.M.A. (EMPA), Editor. 2015.

144. Shao, S., et al., Solubility of argon in laser additive manufactured $\alpha$-titanium under hot isostatic pressing condition. Computational Materials Science, 2017. 131: p. 209-219. 
145. Bagheri, A., M.J. Mahtabi, and N. Shamsaei, Fatigue behavior and cyclic deformation of additive manufactured NiTi. Journal of Materials Processing Technology, 2018. 252: p. 440-453.

146. Sterling, A.J., et al., Fatigue behavior and failure mechanisms of direct laser deposited Ti-6Al-4V. Materials Science and Engineering: A, 2016. 655: p. 100-112.

147. Portolés, L., et al., A qualification procedure to manufacture and repair aerospace parts with electron beam melting. Journal of Manufacturing Systems, 2016. 41: p. 65-75.

148. Gu, J., et al., The strengthening effect of inter-layer cold working and post-deposition heat treatment on the additively manufactured Al-6.3 Cu alloy. Materials Science and Engineering: A, 2016. 651: p. 18-26.

149. Martina, F., S. Williams, and P. Colegrove, Improved microstructure and increased mechanical properties of additive manufacture produced Ti-6Al-4V by interpass cold rolling. 2013.

150. Colegrove, P.A., et al., Application of bulk deformation methods for microstructural and material property improvement and residual stress and distortion control in additively manufactured components. Scripta Materialia, 2017. 135: p. 111-118.

151. Colegrove, P.A., et al., Microstructure and residual stress improvement in wire and arc additively manufactured parts through high-pressure rolling. Journal of Materials Processing Technology, 2013. 213(10): p. 1782-1791.

152. Gu, J., et al. Wire+ arc additive manufacturing of aluminium. in Proceedings of the 25th Annual International Solid Freeform Fabrication Symposium, Austin, TX, USA. 2014.

153. Gu, J., et al., The effect of inter-layer cold working and post-deposition heat treatment on porosity in additively manufactured aluminum alloys. Journal of Materials Processing Technology, 2016. 230: p. 2634.

154. Tapia, G. and A. Elwany, A review on process monitoring and control in metal-based additive manufacturing. Journal of Manufacturing Science and Engineering, 2014. 136(6): p. 060801.

155. Pedersen, D.B., L. De Chiffre, and H.N. Hansen, Additive Manufacturing: Multi Material Processing and Part Quality Control. 2013.

156. De Chiffre, L., et al., Industrial applications of computed tomography. CIRP Annals-Manufacturing Technology, 2014. 63(2): p. 655-677.

157. Rometsch, P.A., et al., Evaluation of polychromatic X-ray radiography defect detection limits in a sample fabricated from Hastelloy $X$ by selective laser melting. NDT \& E International, 2014. 62: p. 184-192.

158. Perraud, J.B., et al., Terahertz imaging and tomography as efficient instruments for testing polymer additive manufacturing objects. Applied optics, 2016. 55(13): p. 3462-3467.

159. Paul, C.P., et al., Investigating laser rapid manufacturing for Inconel-625 components. Optics \& Laser Technology, 2007. 39(4): p. 800-805.

160. Koester, L., et al. Additive manufacturing metrology: State of the art and needs assessment. in AIP Conference Proceedings. 2016. AIP Publishing.

161. Dinwiddie, R.B., et al. Thermographic in-situ process monitoring of the electron-beam melting technology used in additive manufacturing. in Thermosense: Thermal Infrared Applications XXXV. 2013. International Society for Optics and Photonics.

162. Lott, P., et al., Design of an optical system for the in situ process monitoring of selective laser melting (SLM). Physics Procedia, 2011. 12: p. 683-690.

163. Everton, S.K., et al., Review of in-situ process monitoring and in-situ metrology for metal additive manufacturing. Materials \& Design, 2016. 95: p. 431-445.

164. Cherry, J., et al., Investigation into the effect of process parameters on microstructural and physical properties of $316 \mathrm{~L}$ stainless steel parts by selective laser melting. The International Journal of Advanced Manufacturing Technology, 2015. 76(5-8): p. 869-879.

165. Clijsters, S., et al., In situ quality control of the selective laser melting process using a high-speed, realtime melt pool monitoring system. The International Journal of Advanced Manufacturing Technology, 2014. 75(5-8): p. 1089-1101.

166. Berumen, S., et al., Quality control of laser-and powder bed-based Additive Manufacturing (AM) technologies. Physics procedia, 2010. 5: p. 617-622.

167. Craeghs, T., et al. Online quality control of selective laser melting. in Proceedings of the Solid Freeform Fabrication Symposium, Austin, TX. 2011. 
168. Rodriguez, E., et al., Approximation of absolute surface temperature measurements of powder bed fusion additive manufacturing technology using in situ infrared thermography. Additive Manufacturing, 2015. 5: p. 31-39.

169. Seppala, J.E. and K.D. Migler, Infrared thermography of welding zones produced by polymer extrusion additive manufacturing. Additive manufacturing, 2016. 12: p. 71-76.

170. Karnati, S., et al. Vision-based process monitoring for laser metal deposition processes. in Proceedings Solid Freeform Fabrication symposium. 2013.

171. Liu, P., et al., The impact of additive manufacturing in the aircraft spare parts supply chain: supply chain operation reference (scor) model based analysis. Production Planning \& Control, 2014. 25(13-14): p. 11691181.

172. Liu, S., et al., Real-time monitoring of laser hot-wire cladding of Inconel 625. Optics \& Laser Technology, 2014. 62: p. 124-134.

173. Koren, Y., The global manufacturing revolution: product-process-business integration and reconfigurable systems. Vol. 80. 2010: John Wiley \& Sons.

174. Yang, M.G.M., P. Hong, and S.B. Modi, Impact of lean manufacturing and environmental management on business performance: An empirical study of manufacturing firms. International Journal of Production Economics, 2011. 129(2): p. 251-261.

175. Ford, S. and M. Despeisse, Additive manufacturing and sustainability: an exploratory study of the advantages and challenges. Journal of Cleaner Production, 2016. 137: p. 1573-1587.

176. Adam, G.A. and D. Zimmer, Design for Additive Manufacturing-Element transitions and aggregated structures. CIRP Journal of Manufacturing Science and Technology, 2014. 7(1): p. 20-28.

177. Vayre, B., F. Vignat, and F. Villeneuve, Designing for additive manufacturing. Procedia CIrP, 2012. 3: p. 632-637.

178. Salonitis, K., D. Chantzis, and V. Kappatos, A hybrid finite element analysis and evolutionary computation method for the design of lightweight lattice components with optimized strut diameter. The International Journal of Advanced Manufacturing Technology, 2017. 90(9-12): p. 2689-2701.

179. Bandyopadhyay, A. and S. Bose, Additive manufacturing. 2015: CRC Press.

180. Ngo, T.D., et al., Additive manufacturing (3D printing): A review of materials, methods, applications and challenges. Composites Part B: Engineering, 2018.

181. Hölker, R., et al., Hot extrusion dies with conformal cooling channels produced by additive manufacturing. Materials Today: Proceedings, 2015. 2(10): p. 4838-4846.

182. Shinde, M.S. and K.M. Ashtankar, Additive manufacturing-assisted conformal cooling channels in mold manufacturing processes. Advances in Mechanical Engineering, 2017. 9(5): p. 1687814017699764.

183. Lindemann, C., et al. Analyzing product lifecycle costs for a better understanding of cost drivers in additive manufacturing. in 23th Annual International Solid Freeform Fabrication Symposium-An Additive Manufacturing Conference. Austin Texas USA 6th-8th August. 2012.

184. Thomas, D.S. and S.W. Gilbert, Costs and cost effectiveness of additive manufacturing. NIST Special Publication, 2014. 1176: p. 12.

185. Semini, C., et al. Additive manufacturing for agile legged robots with hydraulic actuation. in Advanced Robotics (ICAR), 2015 International Conference on. 2015. IEEE.

186. Arie, M., et al. Performance characterization of an additively manufactured titanium (Ti64) heat exchanger for an air-water cooling application. in ASME 2016 Heat Transfer Summer Conference collocated with the ASME 2016 Fluids Engineering Division Summer Meeting and the ASME 2016 14th International Conference on Nanochannels, Microchannels, and Minichannels. 2016. American Society of Mechanical Engineers.

187. Zegard, T. and G.H. Paulino, Bridging topology optimization and additive manufacturing. Structural and Multidisciplinary Optimization, 2016. 53(1): p. 175-192.

188. Brackett, D., I. Ashcroft, and R. Hague. Topology optimization for additive manufacturing. in Proceedings of the solid freeform fabrication symposium, Austin, TX. 2011. S.

189. Yang, S., Y. Tang, and Y.F. Zhao, A new part consolidation method to embrace the design freedom of additive manufacturing. Journal of Manufacturing Processes, 2015. 20: p. 444-449.

190. Tomlin, M. and J. Meyer. Topology optimization of an additive layer manufactured (ALM) aerospace part. in Proceeding of the 7th Altair CAE technology conference. 2011. 
191. Gardan, N. and A. Schneider, Topological optimization of internal patterns and support in additive manufacturing. Journal of Manufacturing Systems, 2015. 37: p. 417-425.

192. Mani, M., K.W. Lyons, and S. Gupta, Sustainability characterization for additive manufacturing. Journal of research of the National Institute of Standards and Technology, 2014. 119: p. 419.

193. Conner, B.P., et al., Making sense of 3-D printing: Creating a map of additive manufacturing products and services. Additive Manufacturing, 2014. 1: p. 64-76.

194. Javaid, M. and A. Haleem, Additive manufacturing applications in medical cases: A literature based review. Alexandria Journal of Medicine, 2018. 54(4): p. 411-422.

195. Melchels, F.P., J. Feijen, and D.W. Grijpma, A review on stereolithography and its applications in biomedical engineering. Biomaterials, 2010. 31(24): p. 6121-6130.

196. Rosen, D., Design for additive manufacturing: Past, present, and future directions. Journal of Mechanical Design, 2014. 136(9): p. 090301.

197. Shamsaei, N., et al., An overview of Direct Laser Deposition for additive manufacturing; Part II: Mechanical behavior, process parameter optimization and control. Additive Manufacturing, 2015. 8: p. 12-35.

198. Moghaddam, N.S., et al. Enhancement of bone implants by substituting nitinol for titanium (Ti-6Al-4V): A modeling comparison. in ASME 2014 conference on smart materials, adaptive structures and intelligent systems. 2014. American Society of Mechanical Engineers.

199. Amerinatanzi, A., et al. The effect of porosity type on the mechanical performance of porous niti bone implants. in ASME 2016 Conference on Smart Materials, Adaptive Structures and Intelligent Systems. 2016. American Society of Mechanical Engineers.

200. Challis, V.J., et al., High specific strength and stiffness structures produced using selective laser melting. Materials \& Design, 2014. 63: p. 783-788.

201. Vasiliev, V. and A. Razin, Anisogrid composite lattice structures for spacecraft and aircraft applications. Composite structures, 2006. 76(1-2): p. 182-189.

202. Zijm, H., N. Knofius, and M. van der Heijden, Additive Manufacturing and its impact on the supply chain, in Operations, Logistics and Supply Chain Management. 2019, Springer. p. 521-543.

203. Tang, Y., S. Yang, and Y.F. Zhao, Sustainable design for additive manufacturing through functionality integration and part consolidation, in Handbook of sustainability in additive manufacturing. 2016, Springer. p. 101-144.

204. Schmelzle, J., et al., (Re) Designing for part consolidation: understanding the challenges of metal additive manufacturing. Journal of Mechanical Design, 2015. 137(11): p. 111404.

205. Knofius, N., M.C. van der Heijden, and W.H. Zijm, Consolidating spare parts for asset maintenance with additive manufacturing. International journal of production economics, 2019. 208: p. 269-280.

206. Mohammed, M., et al. Applications of 3D topography scanning and multi-material additive manufacturing for facial prosthesis development and production. in Proceedings of the 27th Annual International Solid Freeform Fabrication Symposium. 2016.

207. Zhang, Y., et al., Build orientation optimization for multi-part production in additive manufacturing. Journal of Intelligent Manufacturing, 2017. 28(6): p. 1393-1407.

208. Das, P., et al., Optimum part build orientation in additive manufacturing for minimizing part errors and support structures. Procedia Manufacturing, 2015. 1: p. 343-354.

209. Taufik, M. and P.K. Jain, Role of build orientation in layered manufacturing: a review. International Journal of Manufacturing Technology and Management, 2013. 27(1-3): p. 47-73.

210. Leary, M., et al., Optimal topology for additive manufacture: a method for enabling additive manufacture of support-free optimal structures. Materials \& Design, 2014. 63: p. 678-690.

211. Costabile, G., et al., Cost models of additive manufacturing: A literature review. International Journal of Industrial Engineering Computations, 2017. 8(2): p. 263-283.

212. Piili, H., et al., Cost estimation of laser additive manufacturing of stainless steel. Physics Procedia, 2015. 78: p. 388-396.

213. Ruffo, M., C. Tuck, and R. Hague, Cost estimation for rapid manufacturing-laser sintering production for low to medium volumes. Proceedings of the Institution of Mechanical Engineers, Part B: Journal of Engineering Manufacture, 2006. 220(9): p. 1417-1427.

214. Atzeni, E., et al., Redesign and cost estimation of rapid manufactured plastic parts. Rapid Prototyping Journal, 2010. 16(5): p. 308-317. 
215. Huang, X.X., L.B. Newnes, and G.C. Parry, The adaptation of product cost estimation techniques to estimate the cost of service. International Journal of Computer Integrated Manufacturing, 2012. 25(4-5): p. 417-431.

216. Zhang, Y., et al., Fast adaptive modeling method for build time estimation in additive manufacturing. CIRP Journal of Manufacturing Science and Technology, 2015. 10: p. 49-60.

217. Mehrpouya, M., et al., An artificial neural network model for laser transmission welding of biodegradable polyethylene terephthalate/polyethylene vinyl acetate (PET/PEVA) blends. The International Journal of Advanced Manufacturing Technology, 2019: p. 1-11.

218. Shehab, E. and H. Abdalla, An intelligent knowledge-based system for product cost modelling. The international journal of advanced manufacturing technology, 2002. 19(1): p. 49-65.

219. Tseng, Y.-J. and B. Jiang, Evaluating multiple feature-based machining methods using an activity-based cost analysis model. The International Journal of Advanced Manufacturing Technology, 2000. 16(9): p. 617-623.

220. Priarone, P.C., et al. Assessment of cost and energy requirements of Electron Beam Melting (EBM) and machining processes. in International Conference on Sustainable Design and Manufacturing. 2017. Springer.

221. Son, Y.K., A cost estimation model for advanced manufacturing systems. The International Journal of Production Research, 1991. 29(3): p. 441-452.

222. Schröder, M., B. Falk, and R. Schmitt, Evaluation of cost structures of additive manufacturing processes using a new business model. Procedia CIRP, 2015. 30: p. 311-316.

223. Liu, Z., Economic comparison of selective laser melting and conventional subtractive manufacturing processes. 2017.

224. !!! INVALID CITATION !!! \{\}.

225. Atzeni, E. and A. Salmi, Economics of additive manufacturing for end-usable metal parts. The International Journal of Advanced Manufacturing Technology, 2012. 62(9-12): p. 1147-1155.

226. Rickenbacher, L., A. Spierings, and K. Wegener, An integrated cost-model for selective laser melting (SLM). Rapid Prototyping Journal, 2013. 19(3): p. 208-214.

227. Mellor, S., L. Hao, and D. Zhang, Additive manufacturing: A framework for implementation. International Journal of Production Economics, 2014. 149: p. 194-201.

228. Weller, C., R. Kleer, and F.T. Piller, Economic implications of 3D printing: Market structure models in light of additive manufacturing revisited. International Journal of Production Economics, 2015. 164: p. 43-56.

229. Hopkinson, N. and P. Dicknes, Analysis of rapid manufacturing-using layer manufacturing processes for production. Proceedings of the Institution of Mechanical Engineers, Part C: Journal of Mechanical Engineering Science, 2003. 217(1): p. 31-39.

230. Murr, L., et al., Next-generation biomedical implants using additive manufacturing of complex, cellular and functional mesh arrays. Philosophical Transactions of the Royal Society of London A: Mathematical, Physical and Engineering Sciences, 2010. 368(1917): p. 1999-2032.

231. Kietzmann, J., L. Pitt, and P. Berthon, Disruptions, decisions, and destinations: Enter the age of 3-D printing and additive manufacturing. Business Horizons, 2015. 58(2): p. 209-215.

232. Li, Y., et al., Additive manufacturing technology in spare parts supply chain: a comparative study. International Journal of Production Research, 2017. 55(5): p. 1498-1515.

233. Hasan, S. and A. Rennie, The application of rapid manufacturing technologies in the spare parts industry. 2008.

234. Sirichakwal, I. and B. Conner, Implications of additive manufacturing for spare parts inventory. 3D printing and Additive Manufacturing, 2016. 3(1): p. 56-63.

235. Ben-Ner, A. and E. Siemsen, Decentralization and localization of production: The organizational and economic consequences of additive manufacturing (3D Printing). California Management Review, 2017. 59(2): p. 5-23.

236. Attaran, M., The rise of 3-D printing: The advantages of additive manufacturing over traditional manufacturing. Business Horizons, 2017. 60(5): p. 677-688.

237. Huang, R., et al. Cost Minimization in Metal Additive Manufacturing Using Concurrent Structure and Process Optimization. in ASME 2017 International Design Engineering Technical Conferences and Computers and Information in Engineering Conference. 2017. American Society of Mechanical Engineers. 
238. Chekurov, S., et al., The perceived value of additively manufactured digital spare parts in industry: An empirical investigation. International Journal of Production Economics, 2018. 205: p. 87-97.

239. Tofail, S.A., et al., Additive manufacturing: Scientific and technological challenges, market uptake and opportunities. Materials today, 2018. 21(1): p. 22-37.

240. Pour, M.A. and S. Zanoni, Impact of Merging Components by Additive Manufacturing in Spare Parts Management. Procedia Manufacturing, 2017. 11: p. 610-618.

241. Vineyard, M., K. Amoako-Gyampah, and J.R. Meredith, Failure rate distributions for flexible manufacturing systems: An empirical study. European journal of operational research, 1999. 116(1): p. 139-155.

242. Sterkman, C., Logistical impact of additive manufacturing on the after-sales service supply chain of a spare part provider. 2015, University of Twente.

243. Oettmeier, K. and E. Hofmann, Additive manufacturing technology adoption: an empirical analysis of general and supply chain-related determinants. Journal of Business Economics, 2017. 87(1): p. 97-124.

244. Lindemann, C., et al., Towards a sustainable and economic selection of part candidates for additive manufacturing. Rapid Prototyping Journal, 2015. 21(2): p. 216-227.

245. Knofius, N., et al., Improving effectiveness of spare part supply by additive manufacturing as dual sourcing option. Beta working paper series, 2017(530).

246. Westerweel, B., R.J. Basten, and G.-J. van Houtum, Traditional or Additive Manufacturing? Assessing component design options through lifecycle cost analysis. European Journal of Operational Research, 2018.

247. Kellens, K., et al., Environmental dimensions of additive manufacturing: Mapping application domains and their environmental implications. Journal of Industrial Ecology, 2017. 21(S1): p. S49-S68. 
2019-09-27

\section{Metal additive manufacturing in the commercial aviation industry: A review}

Gisario, Annamaria

Elsevier

Gisario A, Kazarian M, Martina F, Mehrpouya M. (2019) Metal additive manufacturing in the commercial aviation industry: A review. Journal of Manufacturing Systems, Volume 53, October 2019, pp. 124-149

https://doi.org/10.1016/j.jmsy.2019.08.005

Downloaded from Cranfield Library Services E-Repository 